ISSN: 0514-7336 — ISSN electrónico: 2386-3943

DOI: https://doi.org/10.14201/zephyrus202187145166

\title{
¿QUIÉN FUE ENTERRADO EN EL SARCÓFAGO FENICIO ANTROPOIDE MASCULINO DE GADIR (CÁDIZ)?
}

\section{Who is buried into the Phoenician Male Anthropoid Sarcophagus of Gadir (Cádiz)?}

\author{
M.a Milagros Macías López, Ana M.a Niveau-de-Villedary y Mariñas, \\ Natalia López Sánchezy Pablo Sicre GonzÁlez \\ Dpto. de Historia, Geografía y Filosofía. Facultad de Filosofía y Letras-Univ. de Cádiz. Avda. Gómez Ulla, s/n. 11003 \\ Cádiz.Correo-e: mamilama@yahoo.es; anamaria.niveau@uca.es; natalia.lopez@uca.es; pablo.sicregonzalez@ \\ alum.uca.es. ID ORCID: https://orcid.org/0000-0003-1146-3951; https://orcid.org/0000-0002-8888-1169; https:// \\ orcid.org/0000-0001-8985-4675; https://orcid.org/0000-0002-6938-0174
}

Recepción: 16/12/2020; Revisión: 4/03/2021; Aceptación: 25/04/2021

Resumen: El descubrimiento casual del sarcófago antropomorfo sidonio en 1887 despertó una gran expectación tanto entre la población y las autoridades gaditanas como en los especialistas contemporáneos, hasta el punto de que fueron muchos los investigadores que se interesaron por su estudio, así como por el del esqueleto hallado en su interior, aunque nunca se dudó que correspondiera a un varón como presagiaba la representación esculpida en su tapa. Nuestro objetivo con este trabajo es demostrar, por una parte, que la exhibición del esqueleto y los continuos traslados de la pieza provocaron el deterioro irremediable de los restos -del que dan cuenta los estudiosos del momento- y la sustitución de los huesos originales por otros. En segundo lugar, intentaremos determinar el sexo del individuo inhumado mediante el análisis de las fotografías tomadas durante la apertura del féretro y de los primeros estudios antropológicos llevados a cabo en los años inmediatamente posteriores a su hallazgo, antes del reemplazo del esqueleto. A pesar de las dificultades, creemos que contamos con datos suficientes para proponer que, frente a la idea generalizada, los restos originales podrían corresponder a un individuo de sexo femenino.

Palabras clave: fenicios occidentales; tafonomía funeraria; antropología física; determinación del sexo; determinación de la edad; paleopatología.

АвsтRAct: The unexpected discovery of the Sidonian anthropomorphic sarcophagus in 1887 raised great expectation among the population and the authorities of Cadiz, as well as contemporary specialists. Thus, many researchers became interested in the study of both the sarcophagus and the skeleton found inside. The skeleton was presumed to be male as the representation sculpted on its lid presaged. The purpose of this work is to evidence that the exhibition of the skeleton and the piece's continuous transfers caused the irremediable deterioration of the remains over time as it was reported by scholars and the replacement of the original bones for others. Additionally, we aim to determine the sex of the buried individual by analyzing photographs taken during the coffin opening and the first anthropological studies carried out in the immediate years after the discovery before the replacement of the skeleton. Despite the difficulties, we believe to have enough evidence to propose that, in contrast to the widespread perception, the original remains could correspond to an individual of the female sex.

Key words: Western Phoenicians; Funerary Taphonomy; Physical Anthropology; Sex Determination; Age Determination; Paleopathology. 


\section{Introducción ${ }^{1}$}

Los sarcófagos antropomorfos de origen sidonio hallados en Cádiz constituyen dos de las piezas más paradigmáticas de la arqueología

1 Este trabajo se inscribe en el marco de actuación del Grupo de Investigación del PAIDI "Phoenix MEDITERRA$N E A$. Investigación, difusión y transferencia del Patrimonio Histórico-Arqueológico y Cultural de Andalucía Occidental" (нuм-509), del Campus Internacional de Excelencia del Mar (сеIMar) y del Proyecto de I + D $+i$ de Generación de Conocimiento del Ministerio de Ciencia, Innovación y Universidades: "Crisis \& Ritual. Gadir cartaginesa: Estrategias sociales y respuestas rituales en situaciones de crisis" (PGC2018097481-в-г00). Los autores queremos dar las gracias a J. I. Vallejo, director del Museo Provincial de Cádiz, y a M. ${ }^{\mathrm{a}}$ D. López de la Orden, conservadora del mismo, por las facilidades dadas para el estudio de los restos óseos y el ac-

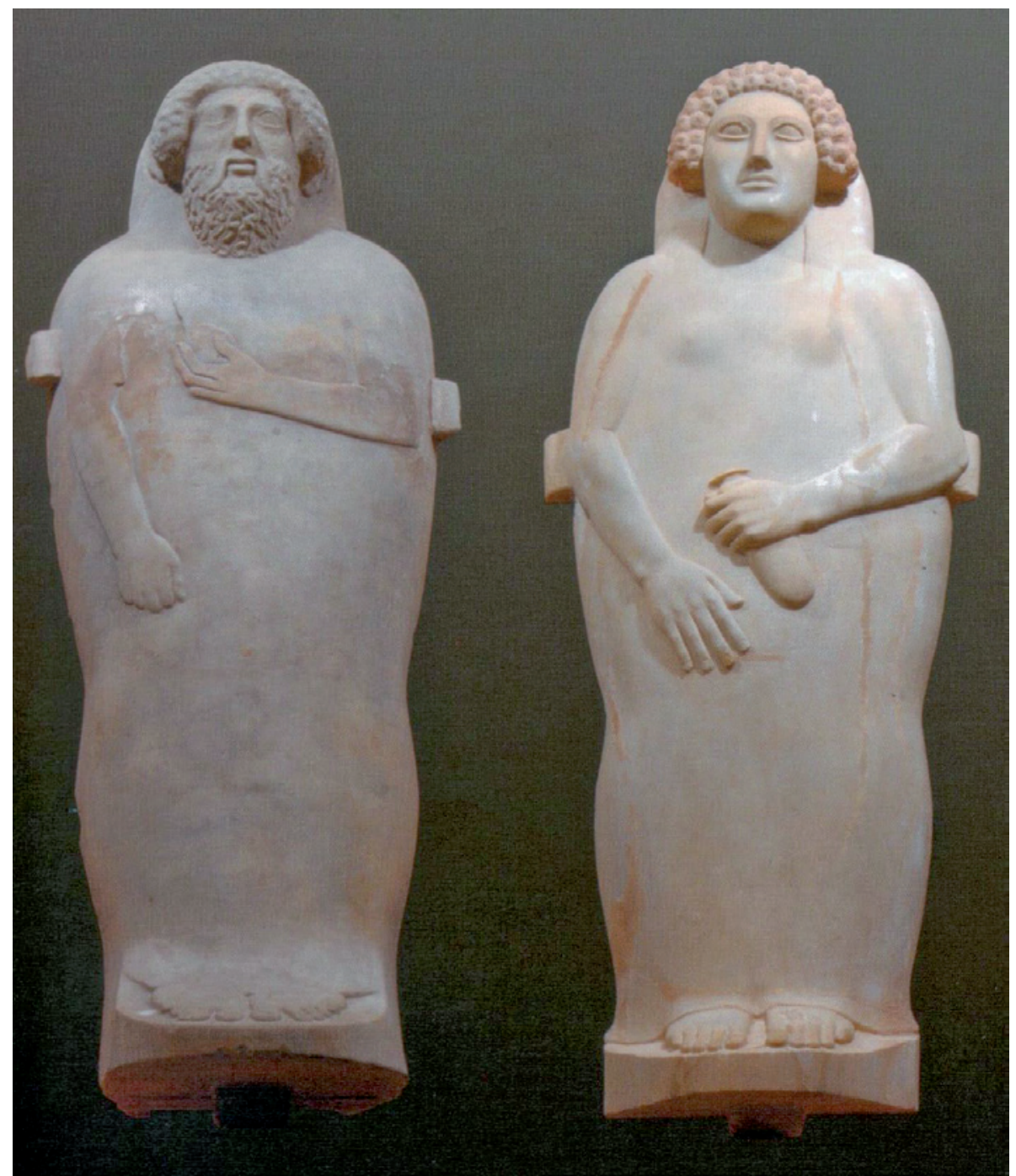

Fig. 1. Sarcófagos antropomorfos de tipo sidonio (imagen cortesía del Museo de Cádiz). ceso a toda la documentación custodiada en la institución, así como por su permanente disponibilidad. A J. R. Ramírez, director del Museo de Las Cortes de Cádiz, por habernos facilitado mucha de la documentación gráfica y bibliográfica de más difícil acceso, así como por sus consejos y apreciaciones. A. Orsingher ha sido nuestro enlace con las Bibliotecas de Tübingen, gracias a él hemos podido consultar algunas obras citadas en el texto. También C. M. Román e I. Alemán nos han proporcionado bibliografía poco accesible. Y, finalmente, no queremos dejar de subrayar la generosidad intelectual y humana de A. Álvarez, a quien agradecemos sinceramente que nos haya permitido consultar y utilizar toda la documentación y notas inéditas de sus investigaciones de comienzos de la década de los ochenta. fenicia de la Península Ibérica (Almagro-Gorbea et al., 2010: 357) y los ejemplares más occidentales hallados en el Mediterráneo (Fig. 1). Se trata de contenedores funerarios derivados de prototipos egipcios. Generalmente se esculpieron en mármol $y$, en principio, estuvieron destinados en exclusiva a las dinastías reales y a su círculo más cercano en la zona de Sidón/Amrit durante la época persa. Los dos ejemplares gaditanos han sido fechados de manera unánime a lo largo del s. v a. C. (Almagro-Gorbea et al., 2010: 389; Torres et al., 
2010a: 37; Torres et al., 2010b: 47, trabajos que recopilan la bibliografía anterior).

El sarcófago masculino se descubrió de forma casual el 31 de mayo de 1887 mientras se allanaban los terrenos de la Punta de la $\mathrm{Vaca}^{2}$ (Fig. 2, n. ${ }^{\circ}$ 1) para el montaje de la Exposición Marítima Nacional que se celebraba ese mismo año. En su tapa se representa un personaje masculino de edad madura, con barba y espesa cabellera, vestido con una túnica o chitón ceñido de manga corta y los pies posiblemente cal-

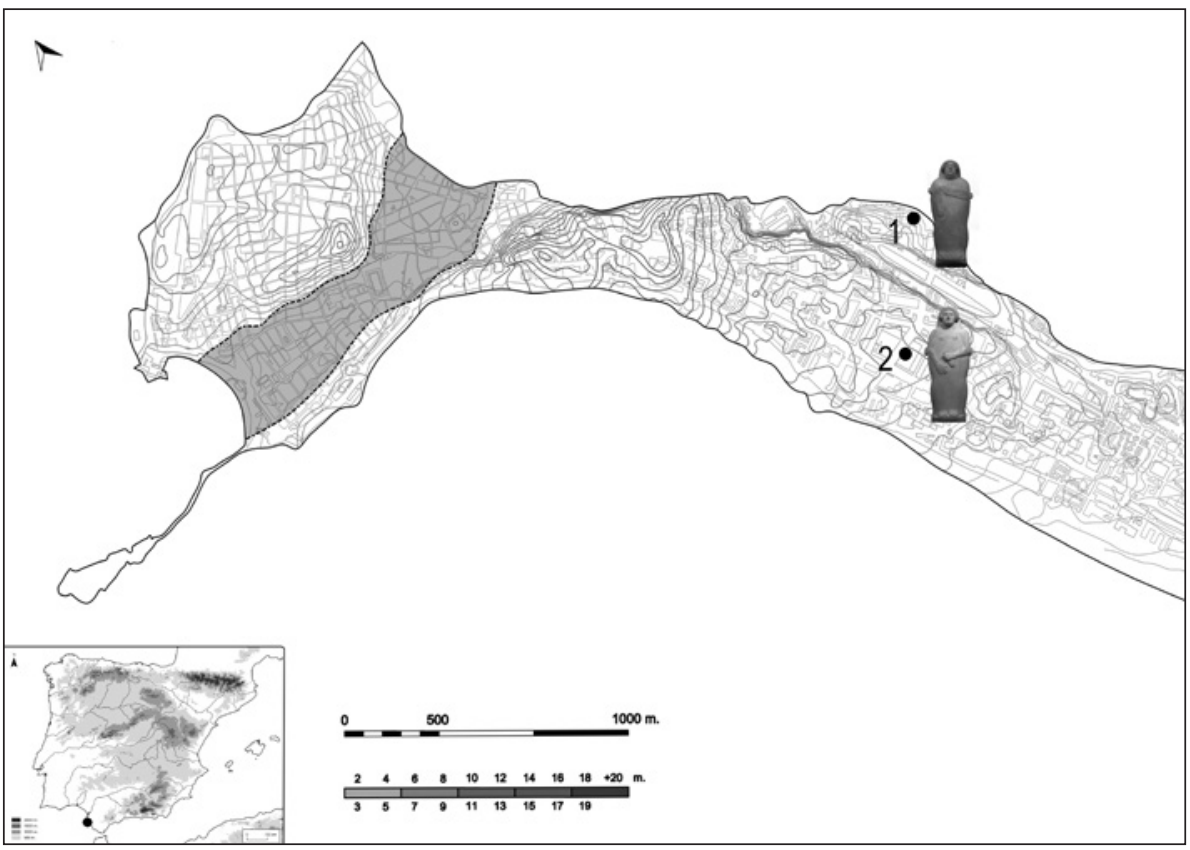

Fig. 2. Plano de Cádiz con la situación de los hallazgos de los sarcófagos: 1) masculino; 2) femenino. zados con unas sandalias pintadas. Su brazo izquierdo, flexionado y recogido sobre el pecho, sostiene una manzana o una granada; el derecho, situado a lo largo de dicho costado con la mano apoyada sobre la pelvis, una corona de laurel pintada (Conte, 1924: 7), hoy desaparecida (Fig. 3). Los primeros estudios estilísticos fueron publicados pronto (Hübner, 1888: 257-258; Rodríguez de Berlanga, 1891: 294-308; Quintero y De las Barras, 1913: 16-17) y desde entonces no han dejado de sucederse trabajos y revisiones en torno a estas cuestiones (por último, Almagro-Gorbea et al., 2010: 389; Torres et al., 2010a: 37). Asimismo, ha sido incluido en los diferentes corpora compilatorios

2 Tras analizar la documentación planimétrica, gráfica y documental disponible, J. A. Fierro Cubiella propone que el lugar exacto de la aparición del sarcófago se corresponda con la parte del parque Celestino Mutis, más cercana a la rotonda que conecta las actuales avenidas de Las Cortes de Cádiz, de La Independencia y de Astilleros, junto al nuevo parque de bomberos de la ciudad tras las diversas reurbanizaciones de la zona; $c f$. http://juanantoniofierro.blogspot. com.es/2013_09_07_archive.html [consulta: 4/12/2020]. Con esta ubicación coincide J. R. Ramírez Delgado, según comunicación personal que agradecemos desde estas líneas.
(Kukhan, 1955: 84, n. ${ }^{\circ}$ 28, fig. 19, tavv. 3, 2, 26, 4, 27; Buhl, 1988, 1991: 680, fig. 4, b; Frede, 2000: 62, 147, tavv. 134-136; Lembke, 2001: 53, n.o 120 , figs. $12,18,19$, tavv. 56-57) $)^{3}$ en las obras de arqueología fenicia generales.

Mucho más reciente es el hallazgo del sarcófago antropomorfo femenino, acaecido el 26 de septiembre de 1980, en un solar de la c/ Ruiz de Alda, actual c/ Parlamento (Corzo, 1979-80; Blanco y Corzo, 1981) (Fig. 2, n. ${ }^{\circ}$ 2). En este caso se representa a una mujer joven peinada con tres filas de bucles, con el rostro sereno, cubierta por un vestido liso. Su mano derecha queda extendida y abierta, mientras que la izquierda se pliega sobre un alabastron alargado con tapadera discoidal (Corzo, 1979-80: 16). Como ajuar se rescataron unas pestañas metálicas, cinco colgantes de loza con forma de ureus y un

3 Por último, Mustafá, B.: La imagen de la realeza en la costa de levante en época persa: arqueología de los sarcófagos antropomorfos fenicios. Tesis doctoral presentada en 2014 en la Univ. de Granada; disponible en https://hera.ugr.es/tesisugr/23798531.pdf; acceso 10/12/2020: 31-33, n. ${ }^{\circ}$ II.101, láms. I.XV, II.XVII y LXXVII-LXXIX. 


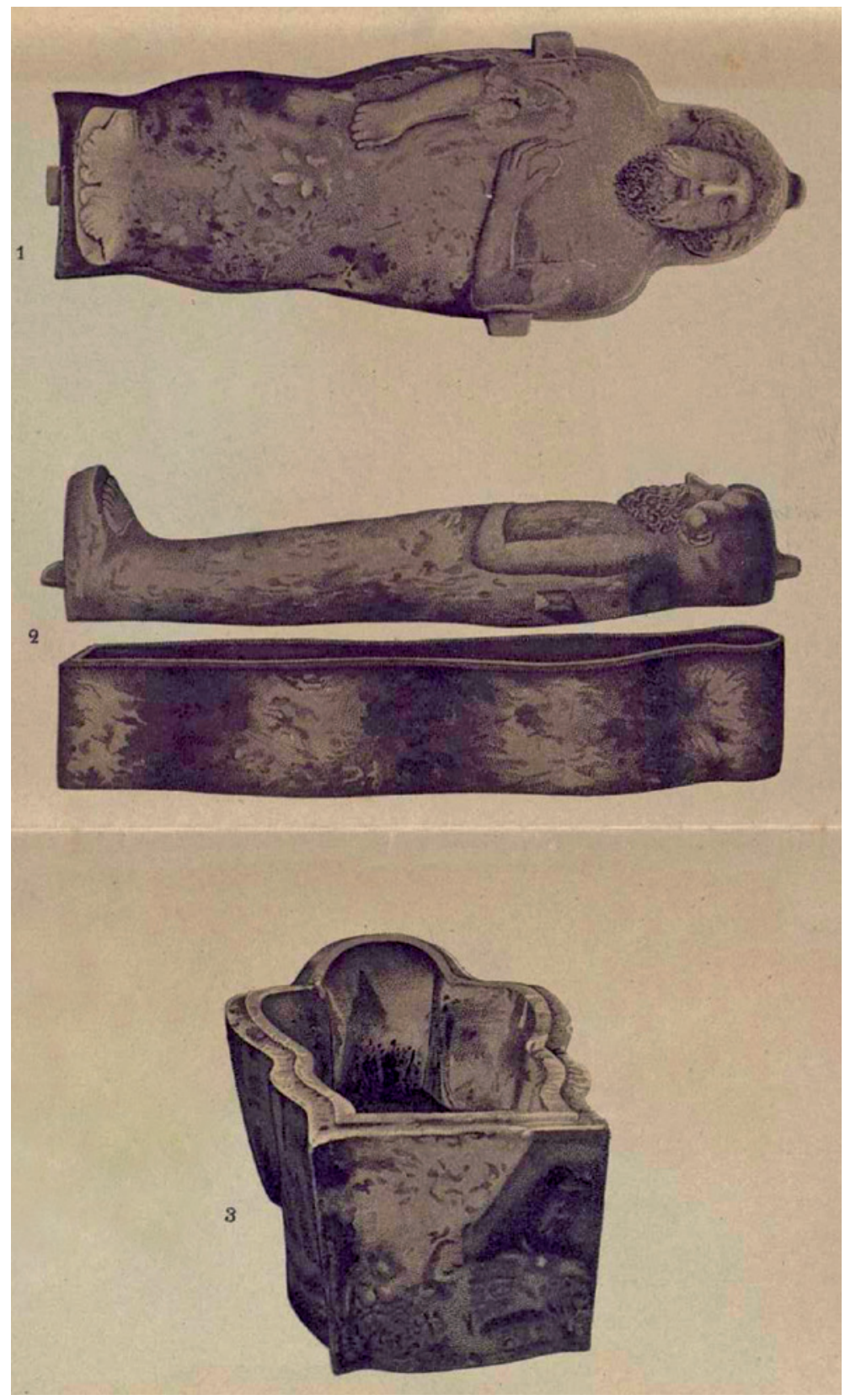

FIG. 3. Reproducción del sarcófago en el momento de su descubrimiento, cuando aún conservaba la corona de laurel pintada en la mano derecha (según Rodríguez de Berlanga, 1891: láms. I y II).

escarabeo en cuyo entalle inferior se representa a un hondero muy musculado en acción de disparar a un sileno (Corzo, 1979-80: 17-18; figs. 9-12; Blanco y Corzo, 1981: 242).
En la última recopilación se contabilizan 126 sarcófagos antropomorfos fenicios, la gran mayoría concentrados en las proximidades de Sidón/Amrit. Tan solo cinco ejemplares llegan hasta el Mediterráneo centro-occidental ${ }^{4}$. La mayor parte proceden de hallazgos fortuitos o son fruto de la búsqueda de anticuarios durante los ss. XVIII y XIX y sus destinos fueron colecciones privadas y museos de todo el mundo. Muy pocos se han recuperado mediante excavaciones metódicas, por lo que de casi ninguno se han conservado los restos óseos humanos 5 $\mathrm{y}$, en ningún caso, han sido estudiados (Mustafá y Abbas, 2015: 23).

Frente a esta ausencia generalizada de restos óseos, en los dos sarcófagos de Cádiz sí se rescataron sus respectivos esqueletos, aunque han corrido distinta suerte. Mientras que los actuales restos óseos del sarcófago masculino que se custodian en el Museo Arqueológico Provincial de Cádiz no son los originales -como demostramos más adelante-, los del sarcófago femenino se conservan en un estado aceptable. En el momento de su descubrimiento en 1980 se dio por sentado que pertenecían a una mujer a pesar de que Antonio Álvarez, que excavó el esqueleto en el interior del sarcófago y lo analizó, manifestó que aquellos restos óseos tenían características indudablemente masculinas. Sin embargo, el impacto que supuso haber descubierto la 'pareja' del sarcófago masculino y el poco interés que el estudio de los restos óseos tenía en la época hicieron que no trascendiera su apreciación.

No será hasta junio de 2019 cuando, al tomar muestras de dichos restos 
óseos con objeto de realizar análisis de $\mathrm{ADN}^{6}$, se advirtió que los huesos pertenecían claramente a un varón, procediéndose entonces a su estudio antropológico y paleopatológico con metodología científica actual. Los resultados obtenidos ${ }^{7}$ nos condujeron a efectuar también una revisión bibliográfica profunda del esqueleto contenido en el sarcófago masculino, ya que desde su descubrimiento hasta nuestros días se había visto envuelto en varias polémicas. El objetivo de este trabajo es intentar poner luz definitivamente a varios de los interrogantes no resueltos en más de un siglo: la supuesta manipulación del esqueleto antes de la apertura oficial del sarcófago, el destino de los restos, su suplantación y, la más reciente, la identidad sexual del individuo inhumado.

\section{La apertura oficial del sarcófago masculino: ¿primera o segunda apertura?}

La primera polémica que se produjo tras el descubrimiento del sarcófago antropomorfo masculino se dio en el mismo momento del acto de su apertura oficial el 1 de junio de 1887, “... del que cumplidamente se levantó acta...", bajo la autoridad de C. del Toro, presidente de la Diputación Provincial en aquel entonces (Conte, 1924: 6) (Fig. 4). Llamó poderosamente la atención a los allí presentes que el esqueleto, en decúbito supino, mostrara "... algunos huesos algo variados de su posición normal...”, concretando C. del Toro “... la posición anómala de los fémures y algunos otros huesos revueltos...” (1901: 90). Tanto Del Toro como Díaz Rocafull, ambos profesores de la Facultad de Medicina de Cádiz, dan la explicación

6 En el marco del Proyecto Internacional "Paleogenetic Study of the Phoenician Period", codirigido por los Dres. P. Zalloua y L. Matisoo-Smith.

Hasta el momento los resultados se han expuesto en diversos foros científicos y de divulgación y la prensa se ha hecho eco de ellos; los resultados científicos se encuentran actualmente en curso de publicación.

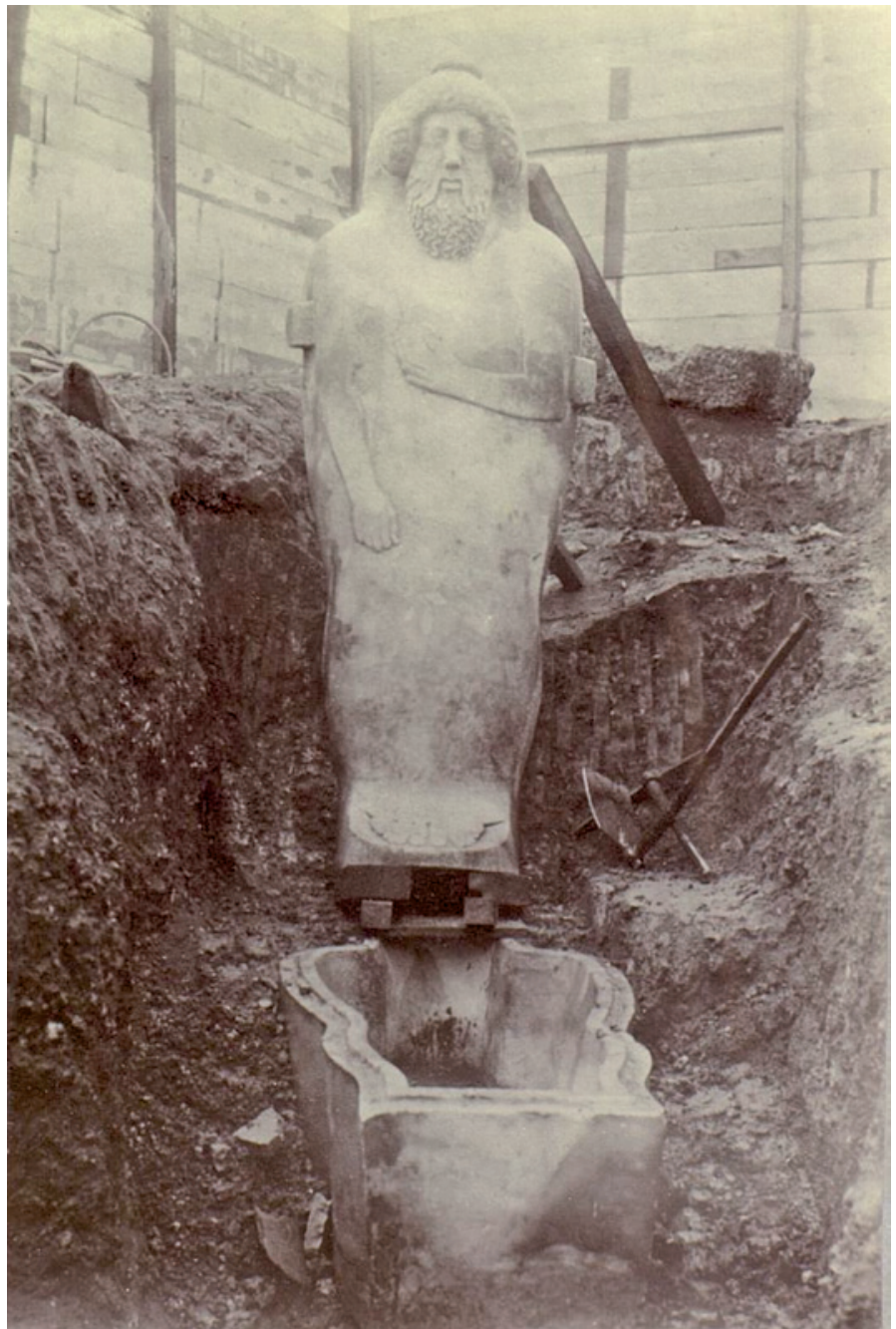

Fig. 4. Sarcófago masculino expuesto en el lugar de su hallazgo (fotografia de R. Rocafull y Monfort; cortesía del Archivo fotográfico del Museo de Cádiz).

de que “... el difunto estuvo enterrado primero en otro sitio y luego, cuando se dispuso del sarcófago, exhumado y trasladado a su interior...”.

La circunstancia anterior, unida a la falta de ajuar, levantó las dudas de que el sarcófago hubiera sido expoliado el día antes de su apertura oficial. Personajes de la época, como Hübner, manifestaron la sospecha de su saqueo entre el día de su descubrimiento (lunes 30 de mayo de 1887) y el de su apertura oficial -el miércoles 1 de junio de 1887-, lo que expuso en noviembre de 1887 ante 
la Sociedad Arqueológica de Berlín (Ramírez, 1982: 170, n. 130) ${ }^{8}$. Ramírez (1982: 170-171, n. 130) apoya este temor poniendo de manifiesto, por un lado, la disparidad de los relatos sobre el ajuar, ya que unos autores refieren la presencia de un fragmento de cuello de ungüentario romano, otros solo de dos clavos (Conte, 1924) y algunos más de cinco clavos, con o sin fragmento de vaso (Quintero y De las Barras, 1913: 16; Rodríguez de Berlanga, 1891: 295; Corzo, 1979-80: 13); y, por otro, la falta de justificación en la tardanza de la apertura del sarcófago y la ausencia en toda la documentación de la época de referencias a una posible violación antigua (Ramírez, 1982: 171, n. 130). Igualmente, Torres y otros (2010a: 26) llaman la atención sobre que en las dos cistas de sillares adyacentes al sarcófago, descubiertas unos días antes, se documentaron “... restos de armas de hierro y huesos de animales labrados...” en una, y, en la otra, un collar de cuentas de pasta vítrea, oro y ágata, un colgante de oro con forma de roseta y un anillo con piedra giratoria labrada en forma de escarabeo, cuyo sello representa una figura femenina (Rodríguez de Berlanga, 1891: 295, 297-298; lám. III), piezas que nunca ingresaron en el Museo (Quintero, 1915: 50) y pasaron a manos particulares. Por nuestra parte podemos añadir dos elementos más de sospecha. Por un lado, el que se levantara una empalizada de madera alrededor del sarcófago para “... resguardarlo de los curiosos...” (Rodríguez de Berlanga, 1891: 299) y, por otro, que el dispositivo para su apertura estuviese perfectamente preparado para hacerlo la tarde del 31 de mayo como recoge la prensa de la época: “... se hicieron varios preparativos para levantar la tapa del sepulcro estableciéndose un aparejo de cabria amarrando perfectamente las cuatro asas...", “... Creíase que ayer tarde [31 de mayo] se verificaría la apertura del sarcófago pero hubo contraorden..." misma. Ante estas circunstancias, no son descabelladas las sospechas de expolio en una época cuya

8 Del Toro sugiere también que la tumba fue profanada “... antes de nuestro hallazgo..." (1901: 90).

9 Diario de Cádiz, 2 de junio de 1887, vuelto a editar en el mismo el 31 de octubre de 1976, p. 9. mentalidad con respecto a los objetos arqueológicos era la propia del coleccionismo privado que desde siglos atrás se venía produciendo en la ciudad y en la provincia, a pesar de que en 1844 se fundó la Comisión Provincial de Monumentos Históricos y Artísticos encargada de las excavaciones arqueológicas. Esta institución carecía de recursos para evitar los saqueos que se siguieron sucediendo en el s. XX (Alonso, 2017: 30-31). No disponer en la ciudad de una instalación museística suponía un grave problema para la conservación del patrimonio arqueológico y un obstáculo real para evitar el expolio. Prueba de las numerosas colecciones privadas que poseían muchas familias gaditanas fue que el Museo se nutrió en gran parte de donaciones particulares desde su nacimiento (Alonso, 2017: 34).

En cualquier caso, la documentación disponible para investigar la posición de los huesos del esqueleto se limita a la única fotografía que existe del mismo, tomada por Rocafull, afamado fotógrafo de la ciudad, en el momento en que se realizó el levantamiento de la tapa del sarcófago en su apertura oficial ${ }^{10}$ (Fig. 5). En ella podemos observar que el esqueleto se encuentra en una posición de decúbito supino con ambos miembros superiores pegados a lo largo del cuerpo sobre un lecho de sedimentos, que según los autores de la época estaba constituido por "... gran cantidad de polvo de madera y varias astillas que parecían de cedro y que se deshacían al tocarlas y fragmentos como de vestido o de sudario; pero ambas cosas muy deshechas..."11 (Rodríguez de Berlanga, 1981: 297).

$\mathrm{Al}$ analizar minuciosamente la fotografía se advierte que en muchas articulaciones no existe una conexión anatómica estricta, pero se aprecia un respeto a la disposición global de los restos esqueléticos, lo que indica que se trata de una inhumación primaria, en contra de la opinión de C. del Toro

10 "Origen fotográfico del Cádiz fenicio", artículo de opinión publicado por R. Garófano en Diario de Cádiz, 4 de mayo de 2004, disponible en https://www.diariodecadiz.es/opinion/articulos/Origen-fotografico-Cadiz-fenicio_0_803919911.html [consultado: 20/11/2020].

${ }_{11}$ Diario de Cádiz, 2 junio de 1887, reproducido en el mismo medio el 31 octubre de 1976, p. 9. 


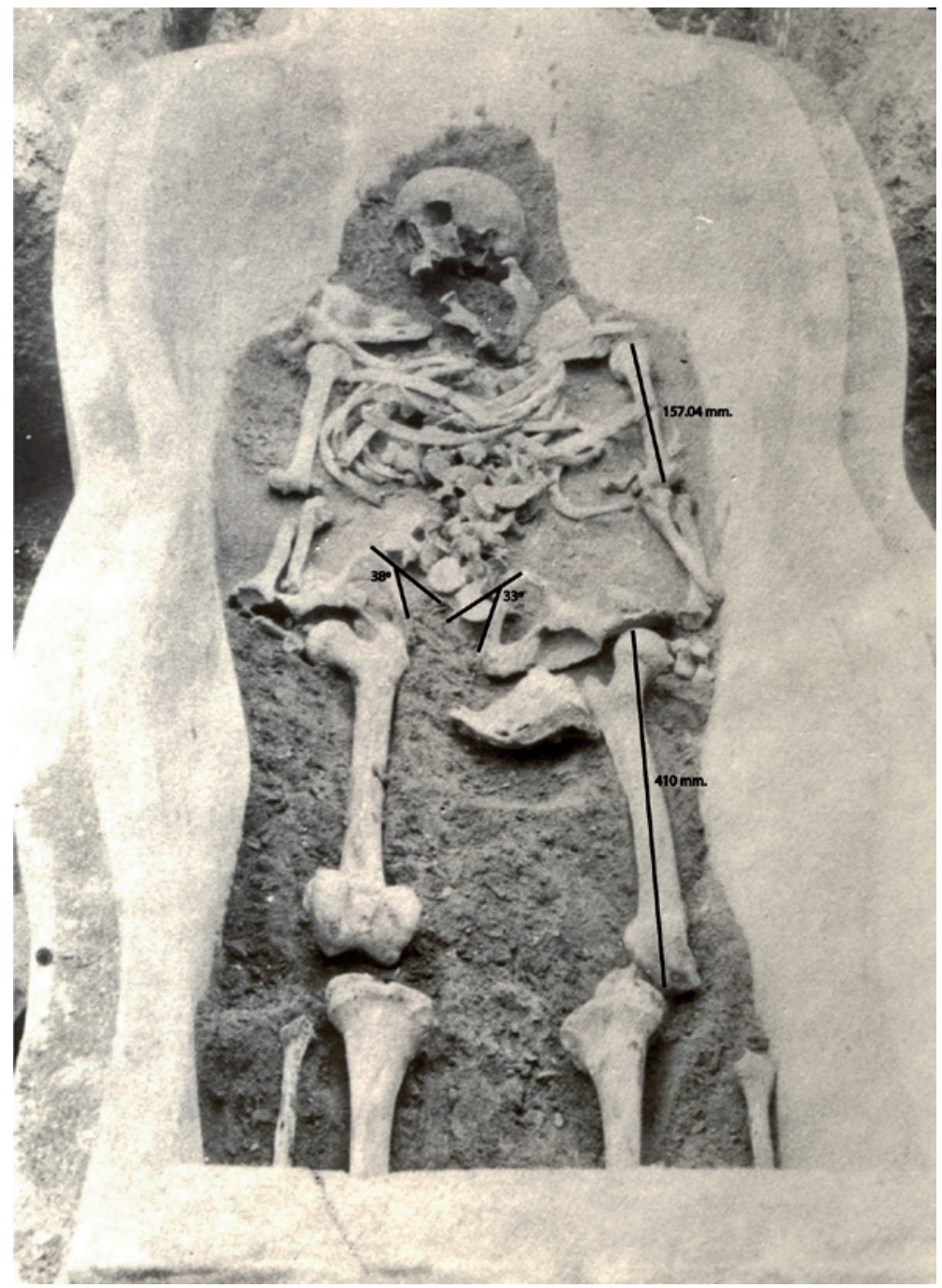

FIG. 5. Imagen de los restos óseos contenidos en el sarcófago fotografiados en el momento de su apertura oficial el 1 de junio de 1887 (fotografía de $R$. Rocafull y Monfort; cortesía del Archivo fotográfico del Museo de Cádiz). desplazamientos fuera del volumen natural del cuerpo (Alapont y Mas, 2015: 384; Duday et al., 2009: 68). En una descomposición en vacío el cuerpo no está cubierto por sedimento y los elementos del esqueleto pueden desplazarse a medida que se pierde la sujeción por los tejidos blandos como resultado de la fuerza de la gravedad y la posición del cuerpo en la sepultura (Santana, 2020: 34; Duday et al., 1990: 31 y 33; 2009: 57). Por lo general, las articulaciones lábiles -interfalángicas y carpianas de la mano, muñeca, huesos del pie, región cervical de la columna, articulación escápulo-torácica, articulación costo-esternal, rótula y hioides- $y$ en inestabilidad gravitacional se desarticulan más rápido, siendo las primeras en dislocarse. Las articulaciones persistentes -las más grandes y resistentes por sus fuertes ligamentos y potente musculatura- lo hacen más lentamente (Duday et al., 1990, 2009; Santana, 2020: 32 y 76). Otros agentes tafonómicos externos que intervienen en el desplazamiento de los huesos en los enterramientos en vacío son las raíces de las plantas y los animales. En nuestro caso descartamos ambos: las primeras porque si las hubiese habido habrían dejado su huella en los huesos y afectado a su integridad, hecho que no coincide con la buena conservación que creía que la posición anómala de algunos huesos se pudiese deber a una deposición secundaria. El cadáver, pues, fue depositado en el sarcófago y su tapa cerrada, por lo que la descomposición del mismo se realizó en vacío.

En este tipo de descomposición se producen una serie de procesos postdeposicionales de origen tafonómico que pueden implicar modificaciones importantes de las situaciones originales de los restos esqueletales, siendo frecuente que existan diferentes grados de desconexión de las articulaciones y que presentaban estos en el momento de su hallazgo. También descartamos la acción de los animales, puesto que el espacio entre la caja del sarcófago y la tapa es demasiado estrecho para que hubiesen podido acceder pequeños roedores.

Todo lo anterior queda reflejado en la fotografía conservada. En efecto, en las articulaciones lábiles como las manos y las escápulo-torácicas se observan algunos huesos del carpo y metacarpo en su lugar anatómico. Sin embargo, el primer metacarpiano de la mano izquierda se encuentra a nivel del codo 
izquierdo y ambas escápulas en un nivel superior al que le corresponde anatómicamente, así como en una posición horizontalizada en lugar de verticalizada, aunque se mantiene la conexión articular del bloque escápulo-calvículo-humeral -hombro-, que constituye una articulación persistente, de lo que se deduce que tardaron más tiempo en descomponerse. Tanto el desplazamiento como la horizontalidad pueden tener su causa en que al ser articulaciones lábiles fueron las primeras en deteriorarse, por lo que coincidiría con la formación de fluidos viscosos por la putrefacción de los tejidos blandos, lo cual pudo provocar arrastre por microcorrientes, favorecidas, si hubo, por una posible pendiente de la superficie de deposición a favor de la parte superior del sarcófago y/o a filtraciones de agua (Santana, 2020: 36; Duday et al., 2009: 77).

En el tronco se aprecia un colapso de las costillas hacia delante y ladeadas a la derecha. Algunas costillas -como la segunda izquierda- se encuentran fuera de su posición anatómica. Asimismo, las vértebras lumbares aparecen revueltas, pero dentro del volumen lógico del cuerpo, lo que podría deberse a distintos tiempos en la descomposición, a la caída en posiciones diferentes o a las microcorrientes viscosas de los fluidos de descomposición y/o a las producidas por agua de filtración; o bien, si hubo ataúd o caja de madera, al colapso de fragmentos de estos sobre los huesos cuyos tejidos de contención habían desaparecido o estaban en proceso de desaparecer.

Por otro lado, la pelvis aparece dislocada, con apertura frontal de las sínfisis púbicas y abierta hacia el exterior, típica de la descomposición en vacío. El ilion derecho aparece desplazado en un plano inferior a su posición anatómica. Una explicación posible pudiera ser que uno de los tablones del hipotético ataúd o tabla que cubría el cadáver colapsara sobre él cuando aún se hallaba en una posición verticalizada, fracturándolo y desplazándolo (Duday et al., 2009: 77). Por su parte, el fémur derecho se encuentra lateralizado hacia el exterior, lo cual es típico de la descomposición en vacío al ser empujado por la apertura de la pelvis (Santana, 2020: 35). Además, el izquierdo muestra su cara posterior que puede ser debido al giro que se produjo al abrirse

Ediciones Universidad de Salamanca / 요요 esta parte de la pelvis, ya que se muestra más abierta hacia el lateral externo que el coxal derecho (Duday et al., 2009: 76 y 111). Igualmente, el peroné izquierdo se observa en su posición anatómica, aunque desplazado lateralmente, tratándose de un tipo de desplazamiento frecuente en los huesos ligeros, ya que estos al desprenderse de sus articulaciones pueden sufrir un rodamiento.

Por último, la rotación de la cabeza hacia el lado derecho se ha producido a consecuencia de la gravedad, ya que una vez han desaparecido los ligamentos que la sujetaban al raquis cervical, al ser el cráneo esférico y, por tanto, inestable sobre una superficie plana, gira hasta que encuentra un tope. Finalmente, la desarticulación y el alejamiento de la mandíbula respecto al bloque cráneo-facial se deben a que la articulación temporo-mandibular se destruye antes que la articulación del raquis cervical, por lo que la mandíbula cae próxima a su lugar anatómico antes de que la cabeza rote hacia un lado (Alapont y Mas, 2015: 386; Duday et al., 2009: 42, 44 y 72 ).

De todo lo anteriormente expuesto podemos deducir que la posición 'anómala' de los huesos apreciada por los presentes en el momento de la apertura del sarcófago es compatible con una descomposición del cadáver en un medio vacío y no puede constituir un elemento de apoyo a la sospecha de expolio del sarcófago previo a su apertura oficial, independientemente de que este se hubiese producido o no.

\section{Los viajes del esqueleto y su suplantación}

La otra gran polémica suscitada durante más de un siglo ha sido la referida a si los restos óseos del sarcófago masculino que se guardan en los fondos del Museo Arqueológico Provincial de Cádiz son los auténticos o no.

La gran trascendencia para la arqueología local que implicó la sucesión de hallazgos arqueológicos en los terrenos de la Punta de la Vaca (Fig. 6) que culminó con el descubrimiento del sarcófago antropomorfo masculino puso en evidencia el 
grave problema que suponía para la conservación del patrimonio arqueológico no disponer de un museo para tal fin (Alonso, 2017: 30). Después de su descubrimiento y tras permanecer expuesto al
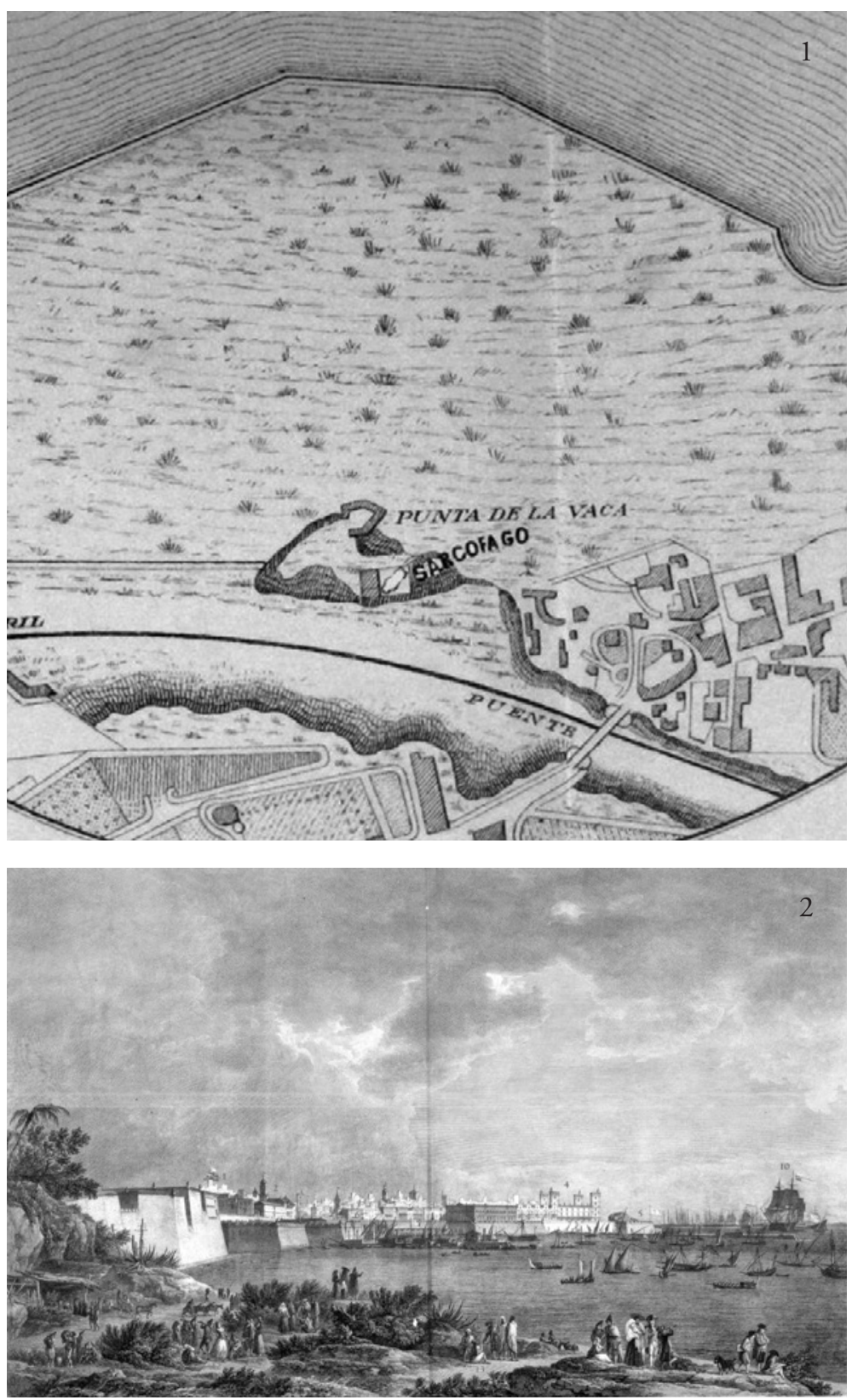

FIG. 6. Imágenes antiguas del lugar del hallazgo: 1) cartografía del s. XIX de Punta de la Vaca (Rodriguez de Berlanga, 1891: lám. v); 2) vista de Cádiz a finales del s. XVIII, Punta de la Vaca en primer término (grabado francés de Noel y Allix, 1782; British Museum, London). público en el pabellón de Antigüedades de la Exposición Marítima, el sarcófago y sus restos fueron trasladaron en diciembre de 1887 a la planta baja de la Escuela de Artes y Oficios, germen del posterior Museo Arqueológico, situada en un pequeño espacio del edificio donde también se ubicaban la Academia y el Museo Provincial de Bellas Artes (Fig. 7). Desde la primera localización hasta la actual se sucedieron, al menos, cinco cambios de sede y dentro de ellas varios cambios de dependencias (Alonso, 2017), siempre en condiciones precarias $^{12}$ (Figs. 8-10). Testimonio de ello

12 El peregrinaje del sarcófago masculino va parejo al del Museo. Cuando se creó en 1887 se instaló en el callejón del Tinte, donde permaneció hasta 1904 en que se trasladó, junto con la Biblioteca, a una finca en la calle Rubio y Díaz. Allí continúa hasta 1907 cuando se vuelve a mover a la c/ Isaac Peral, posterior Avda. Ramón de Carranza y actual avda. 4 de diciembre de 1977, hoy sede de la Biblioteca Provincial. En ambos casos son inmuebles que siguen el modelo de las casas-palacio gaditanas en torno a un patio, lugar en el que se "almacenaron" -en condiciones bastante precarias como demuestran los testimonios fotográficos- las piezas arqueológicas, entre ellas el sarcófago fenicio. No será hasta 1935 cuando el Museo retorne al edificio de la plaza Mina, donde en un primer momento la colección se organiza en torno al patio central. Los sucesos posteriores (entre ellos la Guerra Civil 1936-1939, la explosión del polvorín de la Armada en 1947 y una inundación en 1949) dificultan el acondicionamiento e impiden la apertura definitiva al público, que tras varios intentos tiene lugar en 1970 al fundirse con el Museo de Bellas Artes con el que compartía edificio (no así dirección). La documentación fotográfica conservada en el propio Museo da buena cuenta del "maltrato" al que fueron sometidos tanto los restos óseos, expuestos al aire, como el propio contenedor, sin los más mínimos cuidados o precauciones, colocado directamente sobre el suelo con la única protección de una simple tabla de madera, en espacios sin acondicionar, entre trastos varios y humedades. Hasta 

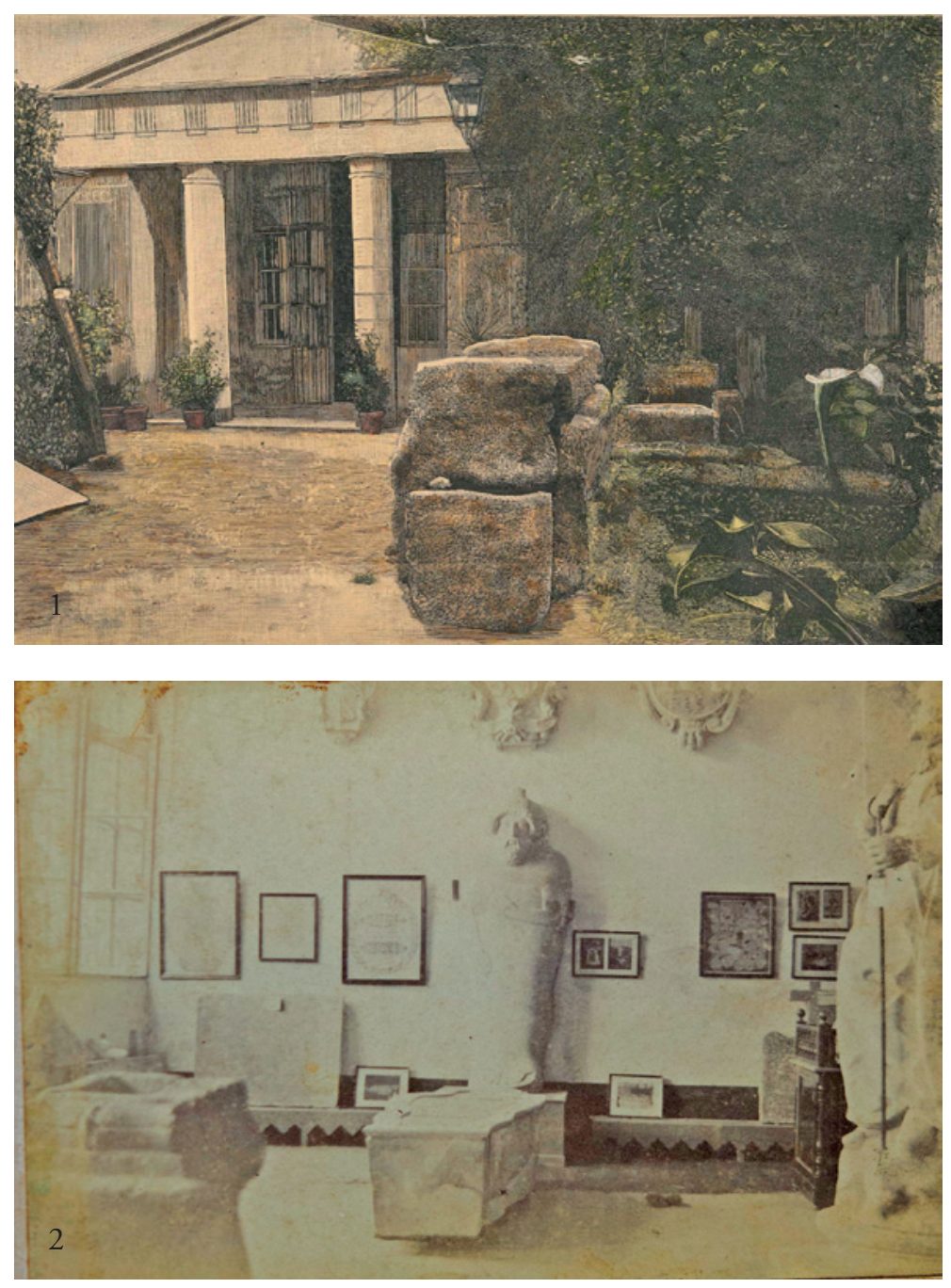

Fig. 7. Sede inicial del Museo Arqueológico Provincial de Cádiz, en el callejón del Tinte: 1) fotografía de los exteriores realizada por $R$. Racafull y Monfort en 1891 (cortesía de J. R. Ramirez); 2) sala abovedada donde se exhibia el sarcófago en 1889 (cortesía del Archivo fotográfico del Museo de Cádiz).

dio P. Quintero, quien en 1910 comentaba el deplorable estado de abandono en que se encontraba el Museo, cerrado al público desde hacía tiempo (1910: 33-34), mientras que Cervera destacaba,

1954 no hay constancia de que la parte inferior de la caja, con el esqueleto en su interior, se protegiera con un cristal y aunque las fotografías realizadas en 1964-65 muestran que los huesos se habían retirado, una vez reinaugurado el Museo en la década de los 70 los restos esqueléticos fueron expuestos de nuevo al público en el interior del sarcófago. una década después, las carencias, la poca luz y las humedades del mismo (1921: 25-32).

Todos estos vaivenes afectaron gravemente a los restos esqueletales del sarcófago, de cuyo deterioro nos han dejado testimonio varios autores. En el momento de su descubrimiento el esqueleto se hallaba perfectamente conservado, como se observa en la fotografía tomada por Rocafull. Rodríguez de Berlanga (1888: 289 y 297), que lo visitó el 26 de septiembre de 1887 , lo encontró aún en el interior del sarcófago en buen estado. Sánchez-Navarro (1890: 18-19), quien realizó su estudio antropológico en $1889^{13}$, dice que se halla en buen estado de conservación excepto la cara. Si observamos la foto de Rocafull la cara del individuo se encuentra indemne, por lo que, en el transcurso de esos dos años la parte más débil del esqueleto, el esplacnocráneo ya sufrió un deterioro visible. Más tarde, Bonsor refiere que vio el esqueleto poco tiempo después de su descubrimiento en perfecto estado, pero que había sido muy maltratado desde entonces debido a las variaciones de local que sufrió el Museo Provincial, por lo que viendo los huesos tan deteriorados se ofreció a “... endurecerlos por el procedimiento de Dolló del Museo de Historia Natural de Bruselas...”, petición que le fue negada por el entonces director del Museo, F. de Vera y Chilier, dándolos por "... irremediablemente perdidos..." (Bonsor, 1922: 166). Este hecho debió ocurrir antes de 1901, pues es la fecha en que el padre Vera fue sustituido

13 Se trata del primer estudio científico de los restos hallados en el sarcófago (Ramírez, 1982: 172, n. 130). Fue publicado parcialmente en la prensa local: Diario de Cádiz, 15 y 16 de febrero de 1890 [reproducido posteriormente en el supl. de 7 de noviembre de 1976], y editado al año siguiente en la Revista Archaeologica del país vecino. 
por P. Riaño de la Iglesia al frente de la institución (Alonso, 2017: 35). Romero de Torres (1934: 50), quien lo visita en 1908, manifiesta que el esqueleto se encontraba “... incompleto de resultas de haber sido maltratado..." en los sucesivos traslados a los que había sido sometido. Posteriormente, en 1912, el Dr. F. de las Barras, catedrático de Antropología Física de la Facultad de Ciencias de Sevilla, interesado por el estudio del individuo del sarcófago fenicio, al no poder hacerse con un ejemplar del trabajo realizado en 1889 por Sánchez-Navarro “... a pesar del empeño con que hemos procurado conseguirlo...", se desplazó a Cádiz para hacer él mismo un nuevo estudio (Quintero y De las Barras, 1913: 17). Este último trabajo es el más conocido, ya que fue reproducido en varias publicaciones de la época de gran difusión (Quintero y De las Barras, 1913, 18-21; Quintero, 1915: 47-49; 1917: 60-62; Romero de Torres, 1934: 52-53), mientras que el realizado por Sánchez-Navarro en 1889 (1890), de más difícil acceso, no tuvo eco en los trabajos posteriores.

Tendría que transcurrir un siglo para que a principios de los años $80 \mathrm{~J}$. R. Ramírez Delgado, durante la realización de su tesis doctoral (1982: 172), consiga un ejemplar del estudio antropológico realizado por Sánchez-Navarro (1890) y se percate de las importantes diferencias que hay con el realizado por De las Barras (1913), concluyendo que se trata de individuos totalmente distintos. También confirmó que los huesos que actualmente se encuentran en el Museo Arqueológico Provincial de Cádiz son los que estudió De las Barras, hecho comprobado también por nosotros.

En nuestra revisión del estudio antropológico del esqueleto realizado por ambos autores, observamos que Sánchez-Navarro (1890) hace una descripción del cráneo morfológica y osteométrica extensa, pero muy escueta del esqueleto postcraneal, limitándose en este último a medir anchura y altura de la pelvis y la longitud de los huesos largos. Analiza 10 características morfológicas del neurocráneo y 11 de la mandíbula, 14 medidas osteométricas del cráneo de los que halla 6 índices, 4 medidas de los huesos largos, 1 del tronco, 2 de la pelvis, 7 índices postcraneales y la longitud total. Sánchez-Navarro no analiza estos datos para averiguar el sexo, que da

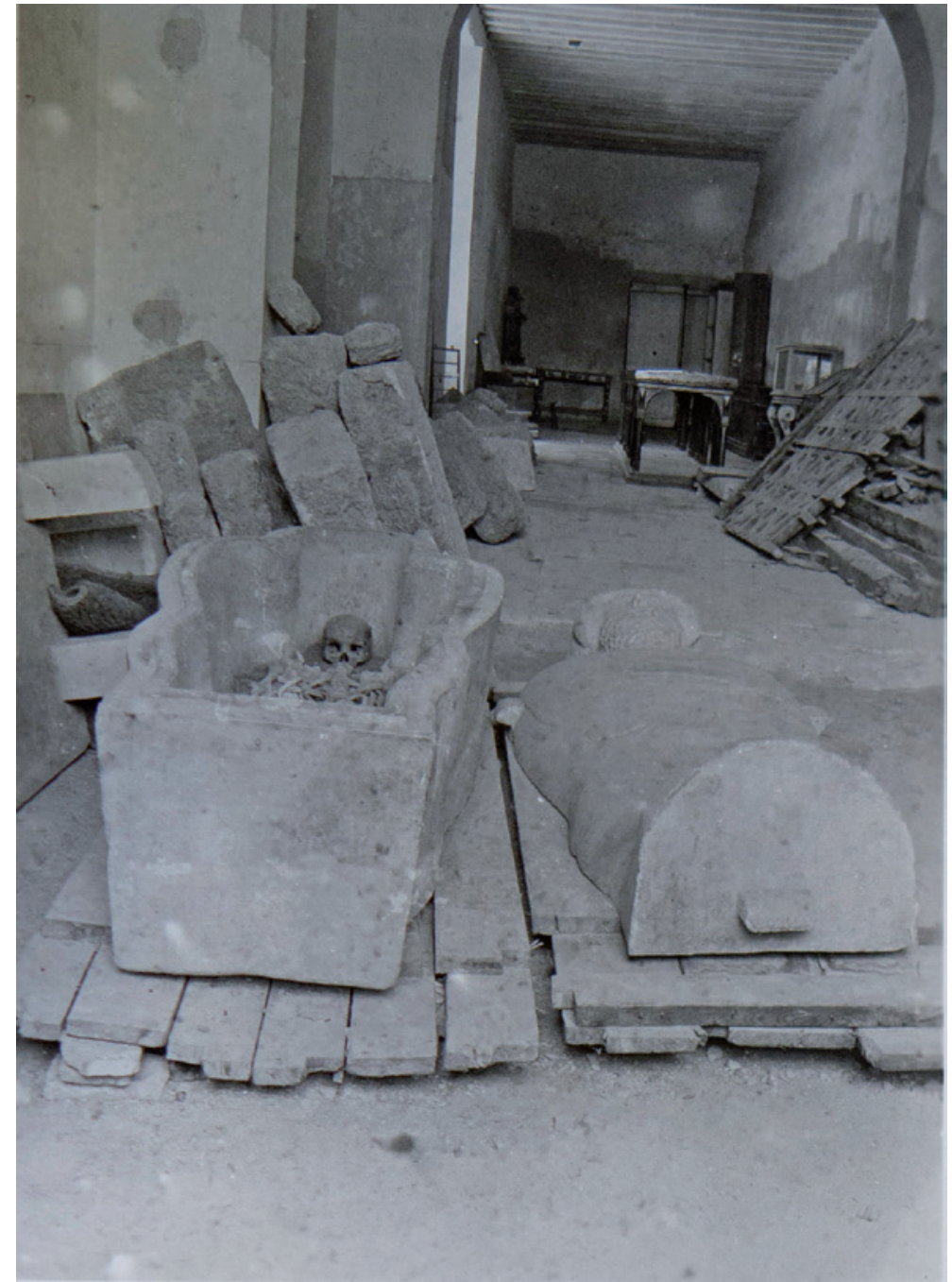

Fig. 8. Fotografía de Fernández-Mier que ilustra el posterior emplazamiento del sarcófago debido al cambio de sede en 1910 del Museo Arqueológico Provincial de Cádiz a la cl Isaac Peral; obsérvense las deficientes condiciones del lugar (cortesía del Archivo fotográfico del Museo de Cádiz). 


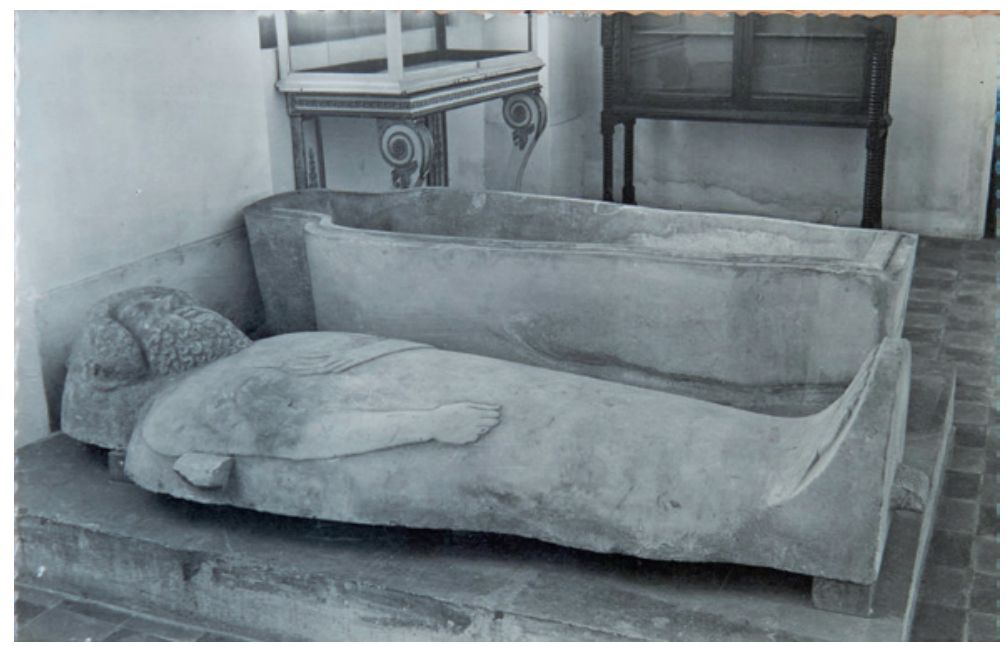

FIG. 9. Fotografia postal de 1949 que ilustra la exposición del sarcófago en el Museo Arqueológico Provincial de Cádiz, entonces en la Plaza Mina, situado en las galerías que rodean el patio central, Sala Fenicia (cortesía del Archivo fotográfico del Museo de Cádiz).

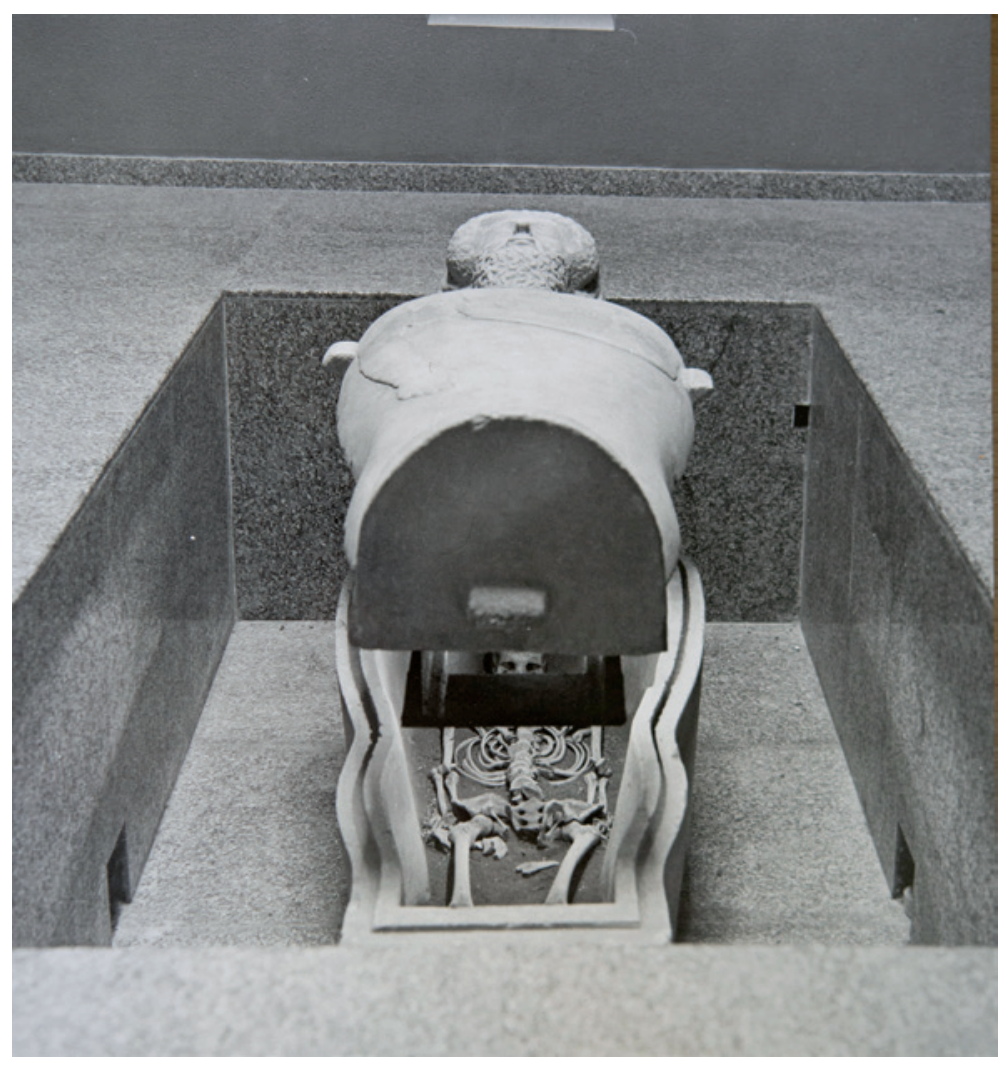

FIG. 10. Exposición del sarcófago masculino con la tapa levantada y el esqueleto en su interior en la reinauguración del Museo, en 1973 (cortesía del Archivo fotográfico del Museo de Cádiz). por hecho -masculino-, sino que centra la discusión en la posible raza del individuo a partir del aspecto general del cráneo y sus medidas.

El posterior estudio de De las Barras (1913) se limita a realizar fundamentalmente mediciones osteométricas. En el neurocráneo toma 17 medidas de las que deduce 6 índices, 11 en esplacnocráneo - sin la mandíbula- con 6 índices, y 17 en huesos largos con 1 índice. Solo refleja 4 características morfológicas del cráneo. No realiza comentario ni discusión alguna sobre los datos analizados $\mathrm{y}$, finalmente, da por hecho que el cráneo es de un individuo masculino.

Al comparar ambos estudios son evidentes las incompatibilidades descriptivas y métricas, siendo las discrepancias más llamativas a nivel craneal, ya que Sánchez-Navarro dice explícitamente que no se encuentran huesos wormianos, que no existe patología alguna y que falta la cara excepto la mandíbula (1890: 18-20). Por el contrario, De las Barras describe claramente la existencia de huesos wormianos en ambos asterion, una lesión exostósica en el parietal izquierdo y obtiene 11 medidas de la cara y ninguna de la mandíbula, porque el esqueleto que él examina no la conserva (Quintero y De las Barras 1913: 19-20; Romero de Torres, 1934: 52-53).

Debido a las diferencias más significativas referentes al cráneo entre ambos estudios antropológicos (Fig. 11), deducimos que en el lapso de tiempo transcurrido entre 1908, última referencia que tenemos de haber visto el esqueleto original (Romero de Torres, 1934: 50) y 1912, debió producirse la sustitución de los restos óseos. La causa de la misma pudo venir condicionada 


\begin{tabular}{|l|l|l|}
\hline $\begin{array}{c}\text { Características } \\
\text { MORFológicas } \\
\text { CRANEALES }\end{array}$ & \multicolumn{1}{|c|}{$\begin{array}{c}\text { M. Sánchez-Navarro } \\
(1890)\end{array}$} & \multicolumn{1}{c|}{$\begin{array}{c}\text { F. de las Barras } \\
(1910)\end{array}$} \\
\hline huesos wormianos & ausentes & en los asterios \\
\hline suturas craneales & $\begin{array}{l}\text { soldadas esfenobasilar } \\
\text { y sagital }\end{array}$ & $\begin{array}{l}\text { sutura sagital complicada; } \\
\text { comienzo de osificación de } \\
\text { extremos sutura coronal }\end{array}$ \\
\hline huesos de la cara & carece & realiza once medidas faciales \\
\hline mandíbula & once características & no se conserva \\
\hline patología & carece de signos patológicos & exóstosis parietal izquierdo \\
\hline
\end{tabular}

Fig. 11. Diferencia entre las características morfológicas del cráneo estudiado por SánchezNavarro y del cráneo estudiado por F. de las Barras.

por la decisión de exponer el sarcófago con su esqueleto, pero al encontrarse este tan deteriorado colocaron otro en buenas condiciones, que es el que actualmente se conserva en los almacenes del $\mathrm{Mu}$ seo Arqueológico de Cádiz y que no se corresponde ni visual ni morfométricamente con el descrito en las primeras publicaciones.

\section{4. ¿Hombre o mujer?}

El hallazgo del sarcófago antropoide femenino en 1980 despertó el interés de A. Álvarez por localizar y revisar los restos óseos del masculino, a sabiendas de que el esqueleto 'oficial' que figuraba en el Museo como perteneciente a este no lo era, lo buscó junto con el entonces director R. Corzo, localizando "... algunas partes [del esqueleto] en los almacenes del Museo de Cádiz, los cinco clavos de bronce que junto con algunos restos de madera constituyen los únicos objetos recogidos en el interior..." (Corzo, 1979-80: 13) ${ }^{14}$. Examinados estos restos, sus apreciaciones no vieron la luz hasta pasadas tres décadas. Es en 2010 cuando A. Álvarez y R. Corzo, en una entrevista realizada con motivo del aniversario del descubrimiento del sarcófago femenino, manifiestan tímidamente que el esqueleto contenido en este presentaba características masculinas y que

14 Sin embargo, todos los esfuerzos realizados en la actualidad para localizar estos restos -los supuestamente originales- y poder acometer un nuevo estudio han sido infructuosos. se tuvieron dudas, en los 80 , sobre si los restos que albergaba el sarcófago masculino pudieran pertenecer a una mujer, llegando a afirmar que “... es posible, quién sabe, que la Dama de Cádiz sea un hombre, y el 'Señor', una mujer"15. Nueve años después, A. Álvarez va más allá y puntualiza con respecto al cráneo del esqueleto del sarcófago masculino: “... el cráneo redondito, la apófisis mastoidea pequeña, de modo que cualquier antropólogo físico diría que es una mujer..."16.

Al no haber sido localizados en los actuales almacenes del Museo los huesos citados por Álvarez y Corzo en dichas entrevistas, hemos intentado poner luz sobre la cuestión de cuál fue realmente el sexo del individuo enterrado en el sarcófago antropoide masculino analizando minuciosamente el estudio antropológico que Sánchez-Navarro hizo del esqueleto original en 1889, con el apoyo de la fotografía realizada al esqueleto en el momento de la apertura del sarcófago, única que existe ${ }^{17}$, y con las apreciaciones que A. Álvarez hizo en 1980, a sabiendas de lo arriesgado de esta empresa.

15 "Los secretos de la Dama de Cádiz", La Voz de Cádiz, 25 de septiembre de 2010, en https:/www.lavozdigital.es/cadiz/20100925/sociedad/secretos-dama-cadiz-20100925.html [consultado: 16/11/2020]. "El Museo difundirá 'la verdad' sobre los sarcófagos a partir de otoño", Diario de Cádiz, 15 de julio de 2019, p. 35. https://www. diariodecadiz.es/ocio/Museo-Cadiz-difundira-verdad-sarcofagos_0_1372363030.html [consultado: 16/11/2020].

16 "El secreto mejor guardado del Museo de Cádiz", Diario de Cádiz, 5 de julio de 2019. https:// www.diariodecadiz.es/cadiz/Dama-Cadiz-hombre-sarcofago-masculino-mujer_0_1369963555. html?utm_source=diariodecadiz $\&$ utm_medium $=$ push \&utm_campaign=La \%20 Dama \% 20 de $\% 20 \mathrm{C} \%$ C3\%A1diz\%20era\%20un\%20hombre\%20y\%20el\%20 sarc $\%$ C3\%B3fago \%20masculino\%2C\%20una $\% 20$ mujer [consultado: 16/11/ 2020].

17 Vid. n. 10. 
La diferenciación sexual en un esqueleto se basa en las diferencias biomorfológicas entre hombres y mujeres. El dimorfismo sexual suele ser evidente entre los adultos, sin embargo, existen individuos denominados alofisos cuya característica reside en poseer rasgos

\begin{tabular}{|c|c|c|c|}
\hline $\begin{array}{c}\text { MARCADOR } \\
\text { ANATÓMICO CRANEAL }\end{array}$ & $\begin{array}{c}\text { según } \\
\text { Sánchez-Navarro }\end{array}$ & $\begin{array}{l}\text { EsTIMACIÓN DEL VALOR según } \\
\text { escala de Buikstra y Ubelaker } \\
(1994: 20)\end{array}$ & $\begin{array}{l}\text { DiAGNÓSTICO } \\
\text { SEXUAL } \\
\text { ESTIMADO }\end{array}$ \\
\hline glabela & "poco apreciable" & Grado $1-2$ & femenino \\
\hline inion & "de pequeńas dimensiones" & Grado 1-2 & femenino \\
\hline \multirow[t]{2}{*}{ mentón } & "casi imperceptible" & Grado 1 & femenino \\
\hline & según Álvarez Rojas & & \\
\hline \multirow[t]{2}{*}{ apófisis mastoides } & "pequeñas" & Grado 1-2 & femenino \\
\hline & documentación gráfica & & \\
\hline borde supraorbital & fino & Grado 1-2 & femenino \\
\hline
\end{tabular}

FIG. 12. Valoración de los marcadores sexuales craneales.

sexuales poco definidos o medidas propias de ambos sexos, dificultando así la labor de determinación sexual. Para averiguar el sexo de un esqueleto se pueden utilizar tres tipos de análisis: morfognósticos -cualitativo-, morfométri$\cos ^{18}$-cuantitativo-y genéticos -análisis de los cromosomas en el ADN-. Los dos primeros serán los que utilicemos pues el tercero es imposible realizarlo por razones obvias.

Todos los autores clásicos (Ferembach et al., 1980; Meindl et al., 1985; Reverte, 1991; Buikstra y Ubelaker, 1994; Ubelaker, 1999; Campillo y Subirá, 2004; Steckel et al., 2006, por citar algunos) están de acuerdo en que las zonas anatómicas más discriminantes para el sexo son, por este orden, la pelvis, el cráneo y el esqueleto postcraneal. Los porcentajes de fiabilidad para cada uno de ellos son, según Meindl et al. (1985), los siguientes: para la pelvis, el $96 \%$; para el cráneo, el 80-90\%; para cráneo + pelvis, el $97 \%$, y para los huesos largos, el $80 \%$.

La zona del esqueleto que Sánchez-Navarro analiza con detalle es el cráneo. De su descripción podemos extraer 10 características morfológicas del neurocráneo y 11 de la mandíbula, así como 14 medidas y 6 índices. La determinación del sexo de un cráneo se ha realizado tradicionalmente en función de una serie de características morfológicas, la cual se puede ver influenciada por la subjetividad. Para minimizarla, se han diseñado métodos

18 Aunque desconocemos el instrumental utilizado y el método seguido por Sánchez Navarro para llevar a cabo sus medidas, las utilizaremos como válidas para este estudio, ya que creemos que las posibles diferencias que pudiese haber no serían demasiado significativas. semicuantitativos de estructuras óseas específicas. El más utilizado es el diseñado por Buikstra y Ubelaker (1994: 20), que valora cinco zonas anatómicas craneales muy discriminantes para el sexo con un rango de variabilidad de 1 a $5-1-2$, femenino; 3, alofiso; 4-5, masculino- y cuya validez ha sido refrendada en recientes estudios, asignándole una eficacia del $75 \%$ cuando se valoran los cinco parámetros (Arriaran et al., 2020). De los cinco indicadores propuestos, Sánchez-Navarro describe tres: glabela, inion y mentón; Álvarez Rojas uno: las apófisis mastoides; y el quinto lo hemos estimado nosotros a partir del documento gráfico. A todos les hemos asignado una valoración estimativa que se plasma en la Fig. 12.

Otras características no semicuantificables pero orientativas en la valoración sexual en el cráneo se recogen en la Fig. 13. Aunque no hay que perder de vista que puede haber varones con rasgos femeninos y viceversa, todos los autores coinciden en que el aspecto general del cráneo en el varón es más grande, más pesado, más anguloso y de rasgos más pronunciados que en la mujer, siendo en esta más pequeño, ligero y grácil. Solamente la suma de todos los parámetros nos dará una idea estimativa del sexo (Brothwell, 1987; Ferembach et al., 1980; Reverte, 1991; Mays, 1998, Ubelaker, 1999; White, 2000).

Para paliar las desventajas de los métodos morfoscópicos se han desarrollado otros basados en la morfometría con análisis multivariantes. Amores ${ }^{19}$

19 Amores, A. (2013): Técnicas de determinación del sexo a partir del cráneo en una población mediterránea actual, p. 55. Tesis doctoral presentada en 2013 en la Univ. 


\begin{tabular}{|c|c|c|}
\hline \multicolumn{2}{|c|}{$\begin{array}{l}\text { CARACTERÍSTICAS MORFOLÓGICAS GENERALES DEL CRÁNEO DESCRITAS POR SÁNCHEZ-NAVARRO } \\
\qquad(1890)\end{array}$} & ESTIMACIÓN SEXUAL \\
\hline \multirow{3}{*}{ aspecto general } & “... se hallan aminorados los caracteres propios del hombre...” & $\begin{array}{l}\text { ¿femenino? } \\
\text { ¿alofiso? }\end{array}$ \\
\hline & $\begin{array}{l}\text { “.. bastante armonioso por ser en él pequeñas todas sus } \\
\text { dimensiones...” }\end{array}$ & Femenino \\
\hline & "... extrańa mezcla de caracteres de superioridad e inferioridad..." & Alofiso \\
\hline paredes parietales & “... poco espesor...” & $\begin{array}{l}\text { probablemente femenino } \\
\text {-depende de la edad- }\end{array}$ \\
\hline fosas temporales & “... poco profundas, inclinadas de arriba-abajo y de fuera a dentro..." & ¿femenino? \\
\hline $\begin{array}{l}\text { aspecto general de la } \\
\text { mandíbula }\end{array}$ & “... bastante pequeńa...” & probablemente femenino \\
\hline tubérculos geni & “... poco desarrollados..." & ¿femenino? \\
\hline $\begin{array}{l}\text { inserciones pterigoideos } \\
\text { internos }\end{array}$ & “... fuertes..." & masculino \\
\hline \multicolumn{3}{|c|}{ CARACTERÍSTICAS MORFOLÓGICAS GENERALES DEL CRÁNEO DESCRITAS POR ÁLVAREZ ROJAS } \\
\hline forma del cráneo & “... cráneo redondito..." & probablemente femenino \\
\hline \multicolumn{3}{|c|}{ CARACTERÍSTICAS MORFOLÓGICAS GENERALES DEL CRÁNEO OBSERVABLES EN LA DOCUMENTACIÓN GRÁFICA } \\
\hline frente & verticalizada & femenino \\
\hline
\end{tabular}

FIG. 13. Valoración sexual de las caracteristicas morfológicas del cráneo.

aplicó este método a una población mediterránea actual ${ }^{20}$ llegando a la conclusión de que el análisis multivariante proporcionaba una fiabilidad del $87 \%$ mientras que el univariante solo del $32 \%$. Las medidas proporcionadas por Sánchez Navarro solamente han permitido el análisis de dos funciones univariantes: la longitud máxima del cráneo -178 $\mathrm{mm}$ - y la altura craneal $-117 \mathrm{~mm}-$, siendo los resultados de mujer para el primero y varón para el segundo ${ }^{21}$.

Con las precauciones oportunas, la mayoría de las valoraciones apuntan a que el cráneo del individuo hallado en el sarcófago masculino puede ser compatible con el sexo femenino. Al no disponer del cráneo, podría plantearse que las características descritas por Sánchez-Navarro pudieran estar relacionadas con un cráneo microcéfalo y, por tanto, la posibilidad de que estuviésemos ante un cráneo patológico. Sin embargo, esta posibilidad la hemos descartado en función de que las medidas están

de Granada; disponible en https://igibug.ugr.es/handle/10481/29952 [consultado: 25/04/2021].

20 Trabajo realizado sobre la colección de Granada del cementerio de San José (Amores, op. cit. n. 19: 59).

${ }^{21}$ Amores, op. cit. n. 19: 144. dentro de la normalidad. Además, al propio autor no se le hubiese pasado por alto esta circunstancia.

La pelvis proporciona la información más fiable en cuanto a la determinación del sexo, llegando al $95 \%$ de fiabilidad. Sánchez Navarro no hace descripción alguna de la pelvis, tan solo se limita a medir su altura y anchura, por lo que no podemos valorar ninguna de las siete zonas anatómicas con alto valor discriminante para el sexo (Ferembach et al., 1980; Buikstra y Ubelaker, 1994; Mays, 1998) ni aplicar las funciones discriminantes que Yoldi et al. (2001) han desarrollado para una población mediterránea actual ${ }^{22}$. Únicamente hemos podido realizar una comparación de una de las variables -la altura del coxal- con los valores absolutos obtenidos en la citada muestra y comparar sus medidas y dos índices obtenidos a partir de ellas con la valoración sexual que de ellos hacen varios autores. Por último, en un intento de aproximarnos a la estimación sexual (Fig. 14), hemos calculado los ángulos subpúbicos de ambos coxales que se aprecian en la fotografía (señalados en la Fig. 5), a sabiendas, no obstante, de que no se encuentran en posición

22 La colección de Granada del cementerio de San José (Yoldi et al., 2001: 24). 


\begin{tabular}{|c|c|c|c|c|}
\hline $\begin{array}{l}\text { VARIABLES PÉLVICAS } \\
\text { VALORADAS }\end{array}$ & $\begin{array}{l}\text { SARCÓFAGO } \\
\text { MASCULINO }\end{array}$ & VALORES SEXUALES & $\begin{array}{l}\text { ESTIMACIÓN } \\
\text { SEXUAL }\end{array}$ & REFERENCIAS BIBLIOGRÁFICAS \\
\hline altura & $200 \mathrm{~mm}$ & $\begin{array}{l}\text { o } 214,3 \pm 10 \\
0197,3 \pm 8\end{array}$ & femenino & Yoldi et al., 2001: 25 \\
\hline anchura & $260 \mathrm{~mm}$ & más ancha que alta & femenino & Reverte, 1991: 586; Ubelaker, 1999: 75 \\
\hline índice general & 130 & & femenino & Testut y Latarjet, 1969: 412 \\
\hline índice de la altura & 76,8 & $\begin{array}{l}0>79 \\
0<74\end{array}$ & alofiso & $\begin{array}{l}\text { Reverte, 1991: 215; Campillo y Subirá, } \\
\text { 2004: } 144\end{array}$ \\
\hline ángulo subpúbico & $\begin{array}{l}66^{\circ *} \\
76^{\circ * *}\end{array}$ & $\begin{array}{l}0<70 \\
0<80\end{array}$ & $\begin{array}{l}\text { varón } \\
\text { alofiso }\end{array}$ & Moore et al., 2013: 379 \\
\hline
\end{tabular}

FIG. 14. Valoración sexual de las medidas de la pelvis: * coxal izquierdo; ** coxal derecho.

\begin{tabular}{|l|c|c|c|c|}
\hline $\begin{array}{c}\text { LONGITUDES } \\
\text { DE LOS } \\
\text { HUESOS LARGOS }\end{array}$ & $\begin{array}{c}\text { VALOR SEXUAL PARA } \\
\text { HOMBRES } \\
(\mathrm{mm})\end{array}$ & $\begin{array}{c}\text { VALOR SEXUAL PARA } \\
\text { MUJERES } \\
(\mathrm{mm})\end{array}$ & $\begin{array}{c}\text { INDIVIDUO } \\
\text { SARCÓfaGO } \\
\text { MASCULINO }(\mathrm{mm})\end{array}$ & $\begin{array}{c}\text { DiAGNÓSTICO SEXUAL } \\
\text { INDIVIDUO SARCÓFAGO } \\
\text { MASCULINO }\end{array}$ \\
\hline húmero & $>330$ & $<280$ & 282 & alofiso \\
\hline radio & $>250$ & $<215$ & 215 & femenino \\
\hline fémur & $>450$ & $<400$ & 410 & alofiso \\
\hline tibia & $>380$ & $<320$ & 332 & alofiso \\
\hline
\end{tabular}

FIG. 15. Medida de los huesos largos y su relación con el posible diagnóstico sexual.

anatómica ni tampoco en el mismo plano, de ahí su limitada fiabilidad. Por tanto, disponemos de pocos datos para estimar el sexo en la pelvis, pero de los seis parámetros medidos, tres apuntan a sexo femenino, dos a alofiso y uno a varón.

Las diferencias sexuales en el resto del esqueleto postcraneal están bien documentadas pero son menos sólidas que las de pelvis o cráneo (Ubelaker, 1999: 75). Morfológicamente se basan en el grado de robustez de los huesos largos, aspecto subjetivo y muy variable de unas poblaciones a otras (Alemán et al., 1997: 69). Sánchez Navarro no realiza descripción alguna del esqueleto postcraneal, pero la observación del documento gráfico muestra la aparente robustez de ambos fémures y de las porciones proximales de las tibias. Es posible que esta apreciación se deba a una distorsión producida por el tipo de lente y el ángulo en que fue tomada la fotografía. Para poder comprobarlo, y aun siendo muy aproximado, hemos comparado la relación longitud del húmero/longitud del fémur medida en la foto (Fig. 5) con las medidas de ambos huesos que nos ofrece Sánchez-Navarro. El resultado es un índice de 0,38 y 0,68 , respectivamente, lo que demuestra la distorsión de la imagen que agranda los elementos que aparecen en primer término, de ahí la aparente robustez de los miembros inferiores que no es tal, por lo que no valoramos este aspecto del esqueleto.

Morfométricamente muchos autores (Reverte, 1991: 596; Ubelaker, 1999; Campillo y Subirá, 2004, entre otros) utilizan hasta dieciséis medidas osteométricas en el esqueleto postcraneal para la estimación sexual. Sánchez-Navarro proporciona solamente cuatro de ellas, siendo estas las menos discriminantes para el sexo (Fig. 15). Sin embargo, la mayor fiabilidad se consigue con la aplicación de funciones discriminantes, aunque solo tienen validez para determinaciones sexuales entre individuos de la misma población o con otras que presenten un dimorfismo sexual similar. En una población mediterránea actual estudiada por Alemán (Alemán et al., 1997), se establecen catorce variables para los huesos largos de miembros superiores y otras catorce para miembros inferiores, con una fiabilidad de la determinación sexual mayor al 80 \% (Alemán et al., 1999: 70 y 72). De las cuatro medidas aportadas por Sánchez Navarro en los huesos largos, solamente la longitud del radio es una variable con 
un porcentaje superior al $80 \%$ en la discriminación sexual. Al no especificar si la medida corresponde al radio derecho o izquierdo hemos aplicado las correspondientes funciones discriminantes para ambos lados. El resultado ha sido: radio derecho: -0,8442705 - punto de corte: -0,052385- e izquierdo: $-0,7862725$ - punto de corte: $-0,07634-$ Al estar ambas por debajo del punto de corte indica que se trata de un individuo femenino con una fiabilidad del $91,46 \%$ y $87,67 \%$, respectivamente (Alemán et al., 1999: 72). La escasez de parámetros postcraneales analizados no nos permite estimar un sexo. No obstante, uno de los parámetros más fiables, como es la longitud del radio, ofrece un sexo femenino.

En resumen, y a pesar de las reservas, al no haber sido tomados los datos directamente por nosotros, la valoración de los parámetros sexuales obtenida en el esqueleto del sarcófago masculino es que se trata probablemente de un individuo femenino: cinco parámetros craneales femeninos -fiabilidad del $75 \%$-; de las diez características generales: ocho probablemente femeninas, una masculina y una alofisa; del análisis univariante: una femenina y una masculina -fiabilidad del $35 \%$-; de la pelvis: tres femeninas, dos alofisas y un varón, y del esqueleto postcraneal: una femenina -fiabilidad del 87-91\%-.

\section{Otros aspectos antropológicos}

Además de la determinación del sexo, a través del estudio de Sánchez-Navarro (1890), podemos aproximarnos a otros aspectos antropológicos como la edad y la estatura. La edad del esqueleto fue ya estimada por varios autores en el momento de su descubrimiento. En los primeros trabajos se afirma “... que los huesos [fueron] reconocidos por personas inteligentes ${ }^{23}$ [que] declararon que pertenecían a un sujeto que debió morir hacia la edad de sesenta años...", aunque no se refiere en función de qué criterios fue calculada (Rodríguez de Berlanga,

23 Se refería a dos reputados profesores de Medicina, los Drs. C. del Toro y E. Díaz Rocafull, presentes en la apertura oficial del sarcófago el 1 de junio de 1887.
1891: 299; Conte, 1924: 7; Ramírez, 1982: 173). Por otra parte, Sánchez-Navarro (1890: 21) le asigna una edad entre 45 y 55 años a partir de la fusión del apéndice xifoides al cuerpo del esternón y a la no fusión del cóccix con el sacro.

La estimación de la edad en esqueletos adultos es complicada debido a la variabilidad existente entre personas en la remodelación ósea continua, más intensa conforme avanza la edad (Campillo y Subirá, 2004: 159). Los mejores métodos para valorar la edad esqueletal propuestos en la actualidad -remodelación de la sínfisis púbica, de la superficie auricular y de los bordes de las costillas- no podemos aplicarlos ya que no se dispone de los restos óseos antiguos y no se describen en el estudio de Sánchez-Navarro. El método clásico, basado en el grado de fusión de las suturas craneales, es el más usado, ya que la calota es una de las partes del esqueleto que mejor suele conservarse frente a las zonas anatómicas citadas anteriormente, que son muy lábiles. El método de obliteración de las suturas craneales está sujeto a diferencias individuales, sexuales y raciales, según algunos autores (Campillo y Subirá, 2004: 160), mientras otros investigadores (Meindl et al., 1985) consideran que esas diferencias no tienen mucha incidencia. Las suturas craneales poseen una secuencia de fusión que ha sido utilizada para establecer modelos de obliteración y su relación con la edad (Olivier, 1960; Meindl y Lovejoy, 1985). Sánchez-Navarro (1890: 20) refiere que solo la sutura esfenobasilar y la sagital se encuentran 'soldadas', pero no especifica en qué grado (Fig. 16). El resto de las suturas: coronal, lambdoidea y escamosa, debían encontrarse sin fusionar dado que el neurocráneo estaba íntegro. La fusión de la sutura esfenobasilar se produce sobre los 21 años y la de la sutura sagital a partir de los 3035 años (Olivier, 1960; Campillo et al., 2004: 160), por lo que en función de ellas la edad calculada sería $>30-35$ años. Además de estas suturas de la calota, también nos ofrece información del estado de una de las suturas palatinas, indicando que no se encuentra fusionada la sutura intermaxilar, entendiendo que las demás -incisiva, intermaxilar y palatomaxilarsí lo estaban. Según Mann et al. (1987), la sutura 


\begin{tabular}{|l|l|c|}
\hline \multicolumn{1}{|c|}{ EDAD } & \multicolumn{1}{|c|}{ CARACTERES VAlorados } & $\begin{array}{c}\text { EDAD ESTIMADA } \\
\text { (AÑOS) }\end{array}$ \\
\hline \multirow{2}{*}{ suturas craneales } & esfenobasilar soldada & $>21$ \\
\cline { 2 - 3 } & sagital soldada & $>30-35$ \\
\hline sutura intermaxilar & no fusionada & $<50$ \\
\hline corona premolar $1 .^{\circ}$ izquierdo & muy desgastada & 45 \\
\hline esternón & fusionado apéndice xifoides & $>40$ \\
\hline coxis-sacro & no fusión & $<60$ \\
\hline
\end{tabular}

FIG. 16. Estimación de la edad.

intermaxilar es la última en fusionarse, a partir de los 50 años, mientras que la sutura palatomaxilar se oblitera alrededor de los 40 años. Deducimos pues, atendiendo a la fusión de estas suturas, que la edad estimada para este esqueleto sería de 40-50 años.

El desgaste dental es otro marcador que podemos utilizar para tratar de estimar la edad, aunque está influenciado fuertemente por la dieta, por las formas individuales de masticación y por las patologías del aparato masticatorio (Krenzer, 2006: 8). A pesar de que en la fotografía del esqueleto se observan claramente los incisivos superiores, no debieron conservarse cuando Sánchez-Navarro examina el esqueleto dos ańos después, pues solo refiere la presencia de un molar inferior izquierdo cuya corona está 'muy desgastada' (1890: 20). Suponemos que en ella ya estaría expuesta la dentina en toda su superficie, por lo que, utilizando el sistema de desgaste dental de Brothwell (1965: 108), le estimamos una edad superior a 45 años.

Otros datos valorables para estimar la edad que ofrece Sánchez-Navarro son la fusión del apéndice xifoides con el cuerpo del esternón que, según Rodes (2004), ocurre a partir de los 40 años, y la no fusión del cóccix al sacro, que ocurre a partir de los 60 ańos. La media de edad valorada por nosotros sería entre 40-50 años, muy cercana a la calculada por Sánchez-Navarro -45-55 años-.

La estatura, al igual que la edad, también ha sido estimada por varios investigadores, resultando bastante heterogéneas sus respectivas apreciaciones. Así, C. del Toro (1901: 90) en el momento de la apertura del sarcófago refiere: "... en el interior se encontraba un hombre de regular talla $(1,445 \mathrm{~m})$ ”. Según
Bonsor (1922: 66), “... el ocupante del sarcófago, cuyo esqueleto tuve ocasión de ver poco tiempo después de su descubrimiento, era un hombre de elevada estatura...”, mientras que Sánchez-Navarro (1890: 19) calcula la estatura en 1,65 m basándose en la medición de la columna vertebral.

Para estimar la estatura a partir de la longitud de los huesos largos proporcionada por Sánchez-Navarro, hemos aplicado los estudios realizados sobre una población española actual ${ }^{24}$, una población portuguesa actual ${ }^{25}$ y una población caucasoide de todo el mundo (Sjovold, 1990, cit. en Barrio y Trancho, 2017: 33) (Fig. 17). Realizando una medida artitmética de los resultados obtenidos, si el individuo fuese masculino se calcula una estatura aproximada de $1,55 \mathrm{~m}$ y si se tratara de una mujer, de $1,53 \mathrm{~m}$.

Esta última talla se aproxima bastante a la dada por Cayetano del Toro, que parece más fiable que las que ofrecen otros autores de su época por su exactitud: 1,445 m. Para obtenerla, debió medir el esqueleto in situ en el momento de la apertura del sarcófago. Aunque Sánchez-Navarro nos ofrece también una medida exacta $-1,65 \mathrm{~m}$-, la calcula solo a partir de una columna vertebral, ya desarticulada, pero que debió volver a articular.

\section{Paleopatología}

Según describe Sánchez-Navarro (1890: 20), en el lado izquierdo de la mandíbula faltan todas las piezas dentarias excepto el 'primer molar'. No hace

24 Belmonte, M. T.: Estimación de la estatura a través de la tibia en población española contemporánea. Tesis doctoral presentada en 2012 en la Univ. de Granada, p. 119; disponible en https://digibug.ugr.es/handle/10481/24014 [consultada: 10/12/2020].

25 De Mendoça, M. C. N.: Contribución para la identificación humana a partir del estudio de las estructuras óseas. Determinación de la talla a través de la longitud de los huesos largos. Tesis doctoral presentada en 2003 en la Univ. Complutense de Madrid; disponible en https://eprints.ucm.es/ id/eprint/2917/ [consultada: 20/ 03/2021]. 
referencia a la presencia o ausencia de las piezas dentarias del lado derecho de la mandíbula ni a ninguna del maxilar superior. En la fotografía de Rocafull se aprecia bien la mandíbula sobre todo su lado izquierdo, que queda en un plano superior con respecto al derecho, que no podemos observar con claridad. En efecto, en el lado izquierdo solo se aprecia una pieza

\begin{tabular}{|c|c|c|c|c|c|c|c|}
\hline \multirow[t]{2}{*}{$\begin{array}{l}\text { ESTIMACIÓN MEDIA DE } \\
\text { LA ESTATURA (m) }\end{array}$} & \multirow[t]{2}{*}{$\begin{array}{l}\text { MEDIDAS DE HUESOS } \\
\text { LARGOS DEL INDIVIDUO } \\
\text { DEL SARCÓFAGO } \\
\text { MASCULINO (MM) }\end{array}$} & \multicolumn{2}{|c|}{$\begin{array}{l}\text { Sjovold, } 1990 \\
\text { cit. en Barrio et } \\
\text { al., 2017: } 33\end{array}$} & \multicolumn{2}{|c|}{$\begin{array}{c}\text { De Mendoça, } \\
\text { 1998: } 92\end{array}$} & \multicolumn{2}{|c|}{$\begin{array}{l}\text { Belmonte, } \\
\text { 2012: } 148\end{array}$} \\
\hline & & ๙ & q & $\hat{0}$ & q & $\hat{\sigma}$ & q \\
\hline longitud del húmero & 282 & 1,49 & 1,49 & 1,52 & 1,51 & ---- & --.-- \\
\hline longitud del radio & 215 & 1,56 & 1,56 & ---- & ---- & --.- & ---- \\
\hline longitud del fémur & 410 & -.--- & ---- & 1,56 & 1,55 & ---- & ---- \\
\hline longitud de la tibia & 332 & -..-- & -..--. & -..- & -..-- & 1,59 & 1,54 \\
\hline ESTATURA ESTIMADA & & 1,52 & 1,52 & 1,54 & 1,53 & 1,59 & 1,54 \\
\hline
\end{tabular}

FIG. 17. Estimación media de la estatura en función de las medidas de los huesos largos. creemos que, según la propia descripción de Sánchez-Navarro (1890: 20), no se trataría del primer molar, sino del primer premolar, ya que afirma: “... la corona del primer molar izquierdo [...] habiendo desaparecido el canino a él contiguo...”, deduciéndose que este autor consideraba molares a los premolares, un hecho más acorde con la posición de la pieza dentaria que se observa en la fotografía.

Además, describe el aspecto de la mandíbula en su lado izquierdo como 'corroída' precisamente en el sitio que debieron ocupar los molares. No podemos saber qué quería decir exactamente al calificar la mandíbula con ese término, pero es probable que hubiese defectos en el tejido óseo que pudieran deberse bien a procesos tafonómicos o bien a verdaderas lesiones patológicas, probablemente alveolares. Por otra parte, especifica que el alvéolo del canino izquierdo se encuentra soldado y “... notándose bajo el sitio que debió ocupar el maxilar desgastado por la caries padecida mucho antes de morir, por hallarse restablecida la lámina vítrea, no obstante, lo profundo de la lesión..." (Sánchez-Navarro, 1990: 20). De esta descripción podemos deducir que este individuo tuvo al menos la pérdida ante mortem del canino izquierdo, pero también que la causa de tal pérdida se debió a un absceso apical de gran tamaño con destrucción, y posterior reparación, de la cortical mandibular a nivel del mismo, lo que le debió producir un gran quiste o granuloma.

\section{Conclusiones}

Pensamos que, tras la revisión realizada y mostrada en este trabajo, las polémicas suscitadas desde el instante en que se abrió oficialmente el sarcófago antropoide masculino han podido quedar más esclarecidas. Por un lado, se descarta que la malposición de algunos de los huesos del esqueleto fuese debida a un enterramiento secundario o a causa de la acción del expolio, sino que fue originada por los procesos tafonómicos propios de la descomposición del cadáver en un medio en vacío. Ello no es incompatible con que el expolio se hubiera podido producir, como sospecharon algunos autores en su época e incluso en la actualidad. Por otro lado, queda totalmente demostrado que los restos óseos que actualmente se conservan en el Museo Arqueológico de Cádiz como pertenecientes al sarcófago antropoide masculino no son los hallados en él, sino que el esqueleto original sufrió tal deterioro que fue sustituido entre 1908 y 1912 (Ramírez, 1982: 173, n. 130) por otro en buen estado de conservación y cuyos huesos proceden probablemente de dos individuos diferentes. En cuanto a la polémica respecto a su verdadero sexo, consideramos que el esqueleto del sarcófago masculino puede ser compatible con un individuo femenino, con una edad entre 40-50 años y 1,53-1,55 m de estatura, que padeció la pérdida ante mortem de varias piezas dentarias inferiores 
y, al menos, un absceso apical con destrucción de la cortical a nivel del canino inferior izquierdo.

El estudio antropológico del esqueleto del sarcófago masculino por parte de Sánchez-Navarro en 1889 (1890) estuvo condicionado desde su inicio, por un lado, porque nunca se cuestionó que el individuo pudiera no ser un varón, a pesar de que las características anatómicas que describe fuesen más compatibles con un individuo femenino; y, por otro, porque lo que realmente le interesaba era conocer su raza, acorde con la mentalidad de la época. Para establecer una coherencia entre los caracteres masculinos tan mermados en el esqueleto y un varón solo pudo recurrir a degradarlo como hombre, relacionando su cráneo pequeño con un minusválido mental -definido como 'estúpido' a finales del XIX-, mostrando su gran decepción respecto a la masculinidad del individuo al considerar que este tipo de personas eran indignas de enterrarse en una sepultura tan exclusiva como este sarcófago.

Del más de un centenar de sarcófagos fenicios documentados hasta el momento solo de los dos aparecidos en Cádiz se ha realizado el estudio de sus respectivos esqueletos. En ambos casos se confirma que no se produce una identificación sexual entre las figuras esculpidas en la tapa del sarcófago y el sexo del individuo enterrado en él. Con base en ello, y una vez descartada la procedencia occidental del mármol con el que se elaboraron (Lapuente et al., 2020: 11), cobra fuerza la hipótesis de que estos sarcófagos llegaran a Cádiz desde los talleres orientales y lo hicieran no como encargos expresos, sino, más probablemente, a modo de dones o regalos destinados a la oligarquía económica, política o religiosa de la ciudad occidental, como forma de sellar los pactos mercantiles entre Estados, en un momento en que tanto las fuentes escritas como los restos materiales evidencian la plena inclusión y el peso de Gadir en los circuitos comerciales mediterráneos de la mano de las salazones de pescado (García y Ferrer, 2012).

En cualquier caso, la presencia excepcional de los sarcófagos sidonios en Gadir no haría sino recalcar la riqueza y el dinamismo alcanzados por la antigua fundación tiria durante el s. v a. C.

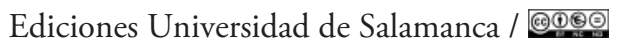

(Niveau-de-Villedary, 2015: 237), cuya oligarquía gozaría de la capacidad y la posición social suficiente para procurarse estos objetos de lujo a través de una red de intercambio elitista a nivel mediterráneo que le permitiría emular, en la lejanía, a la propia monarquía oriental, al menos en el momento de la muerte. En este caso, la verdadera importancia para el difunto, para su familia y para la comunidad era el contenedor funerario en sí, el sarcófago, y no tanto la identificación con la figura representada en su tapa.

\section{Bibliografía}

Alapont, L. y Mas, P. (2015): "Reconstrucción y representación de los gestos funerarios a partir del estudio antropológico". En Actuacions sobre el patrimoni Aqueologic de la Comunitat Valenciana. Actes I Jornades d'Arqueologia de la Comunitat Valenciana. Valencia: Ayto. de Valencia, pp. 381-394.

Alemán, I.; Botella, M. C. y Du Souich-Henrici, P. (1999): "Aplicación de las funciones discriminantes en la determinación del sexo", Estudios de Antropología Biológica, IX, pp. 221-230. Disponible en http:// www.revistas.unam.mx/index.php/eab/article/ view/30818

Alemán, I.; Botella, M. C. y Ruiz, L. (1997): “Determinación del sexo en el esqueleto postcraneal. Estudio de una población mediterránea actual”, Archivo Español de Morfología, 2, pp. 69-79.

Almagro-Gorbea, M.; López, M. E.; Mederos, A. y Torres, M. (2010): "Los sarcófagos antropoides de la necrópolis de Cádiz”, Mainake, xxxiI (1), pp. 357-394. Disponible en https://dialnet.unirioja.es/ servlet/articulo? codigo $=3643483$

Alonso de la Sierra, J. (2017): “El Museo Arqueológico Provincial de Cádiz (1887-1970)", Boletín del Museo Arqueológico Nacional, 35, pp. 29-42. Disponible en http://www.man.es/man/dam/jcr:e48e2d87-d70946dd-888f-7483a954635a/man-bol-2017-35-003. pdf

Arriarán, L.; Vigo, C. y Velezmoro, I. (2020): "Eficacia de los métodos de Buikstra \& Ubelaker y Ferembach, en la estimación del sexo en cráneos humanos procedentes del departamento de Ayacucho, Perú", Revista Mexicana de Medicina Forense y Ciencias de la Salud, 5 (4), pp. 24-35. Disponible en https://www. 
medigraphic.com/cgi-bin/new/resumen.cgi?IDARTICULO $=96963$

Barrio, P. A. y Trancho G. J. (2017): "Estudio de la estatura a partir de los huesos de la extremidad superior de la población hispano-musulmana de San Nicolás (Ávila)", Revista Española de Antropología Física, 38, pp. 29-43. Disponible en http://seaf.es/index. $\mathrm{php} /$ revista-reaf/173-volumen-38-2017

Blanco, A. y Corzo, R. (1981): "Der neue anthropoide sarkophag von Cádiz", Madrider Mitteilungen, 22, pp. 236-243.

Bonsor, J. (1922): “El Coto de Dońa Ana. Una visita arqueológica", Boletín de la Real Academia de la Historia, LXxxI, pp. 52-174. Disponible en http://www. cervantesvirtual.com/portales/boletin_real_academia_historia/obra/el-coto-de-dona-ana-una-visita-arqueological

Brothwell, D. R. (1987; $3^{\text {rd }}$ ed.): Digging up bones. The excavation, treatment and study of human skeletal remains. Ithaca-New York: Cornell University Press. Disponible en https://books.google.es/books/about/ Digging_Up_Bones.html?id=IMH3oomzIoEc\&redir_esc $=y$

BuHL, M. L. (1988): "Les sarcophages anthropoïdes phéniciens en dehors de la Phénicie", Acta Archéologique, 58, pp. 213-221.

Buhl, M. L. (1991): "Les sarcophages anthropoides phéniciens trouvés en dehors de la Phénicie". En Atti II Congresso Internazionale di Studi Fenici e Punice (Roma, 1987). Roma: Consiglio Nazionale delle Ricerche, vol. II, pp. 675-681.

Buikstra, J. E. y Ubelaker, D. H. (1994): Standards for Data Collection from Human Skeleton remains. Research Series, 44. Fayetteville: Arkansas Archeological Service.

Campillo, D. y Subirá, E. (2004): Antropología física para arqueólogos. Barcelona: Ariel-Prehistoria.

Cervera, F. (1921): "Recuerdo y Obsequio del Museo Arqueológico Provincial de Cádiz", Boletín de la Comisión Provincial de Monumentos de Cádiz, 2. a época, II, pp. 25-32.

Conte, A. J. (1924): "De historia y arte. El Museo Arqueológico", Brotes Juveniles, año II, 14, pp. 6-7.

Corzo, R. (1979-80): "El nuevo sarcófago antropoide de la necrópolis gaditana", Boletín del Museo de Cádiz, II, pp. 13-24.

Duday, H.; Cipriani, A. N. y Pearce, J. (2009): The archeology of the dead. Lectures in archeothanatology. Oxford: Oxbow Books.
Duday, H.; Courtaud, P.; Crubezy, E.; Sellier, P. y Tillier, A.-M. (1990): "L'Anthropologie 'de terrain': reconnaissance et interprétation des gestes funéraires", Bulletins et Mémoires de la Société d'Anthropologie de Paris. Nouvelle Série, 2 (3-4), pp. 2949. DoI: https://doi.org/10.3406/bmsap.1990.1740

Ferembach, D.; Schwidetzky, I. y Stloukal, M. (1980): "Recommendations for Age and Sex Diagnoses of Skeletons", Journal of Human Evolution, 9, pp. 517-549. DoI: https://doi.org/10.1016/00472484(80)90061-5

Frede, S. (2000): Die phönizische anthropoiden Sarkophage I. Fundgruppen und Bestattungskontexte. Mainz: Verlag Philipp Von Zabern.

García, E. y Ferrer, E. (2012): "Más allá del banquete: el consumo de las salazones ibéricas en Grecia (siglos v y IV a. C.)". En Sal, pesca y salazones fenicios en Occidente. XXVI Jornadas de Arqueología fenicio-púnica (Ibiza, 2011). Treballs del Museu Arqueològic d'Eivissa i Formentera, 67. Eivissa: MAEF, pp. 85-121.

Hübner, E. (1888): La Arqueología de España. Barcelona: Tipo-Litografía de los Sucesores de Ramírez y C. ${ }^{a}$.

Krenzer, U. (2006): Compendio de métodos antropológico forenses para la reconstrucción del perfil osteo-biológico. Serie de Antropología Forense, t. III. Guatemala: CAFCA.

KukHan, E. (1955): Anthropoide Sarkophage in Beyrouth und die Geschichte dieser Sidónischen Sarkophag kunst. Berlin: Ed. Mann.

Lapuente, P.; RodÀ, I.; Gutiérrez García, M. A. y BRILli, M. (2020): "Addressing the controversial origin of the marble source used in the Phoenician Anthropoid Sarcophagi Of Gadir (Cadiz, Spain)", Archaeometry, pp. 1-14. Dor: https://doi. org/10.1111/arcm.12623

Lembke, K. (2001): Phönizische anthropoide Sarkophage. Mainz: Verlag Philipp Von Zabern.

Mann, R. W.; Symes, S. A. y Bass, W. M. (1987): "Maxillary suture obliteration: Ageing the human skeleton based on intact or fragmentary maxilla", Journal of Forensic Sciences, 32, pp. 148-157. DoI: https://doi.org/10.1520/JFS12337J

Mays, S. (1998): The archaeology of human bones. London-New York: Routledge.

Meindl, R. S. y Lovejoy, C. O. (1985): "Ectocranial suture closure: A revised method for the determination of skeletal age at death and blind tests of its accuracy", American Journal of 
Physical Anthropology, 68, pp. 57-66. DoI: https:// doi.org/10.1002/ajpa.1330680106

Meindl, R. S.; Lovejoy, C. O.; Mensforth, R. P. y Carlos, L. D. (1985): "Accuracy and direction of error in the sexing of the skeleton", American Journal of Physical Anthropology, 68, pp. 79-85. DOI: https:// doi.org/10.1002/ajpa.1330680108

Moore, K.; Dailey, A. y Agur, A. (2013; 7. a ed.): Anatomía con orientación clínica. Barcelona: Wolters Kluwer Health, sA-Lippincott Williams \& Wilkins.

Mustafá, B. y Abbas, N. (2015): "New marble sarcophagus from Syrian coast", Scientific Culture, 1 (1), pp. 17-26. Disponible en https://sci-cult.com/ wp-content/uploads/2018/04/1_3.pdf

Niveau-De-Villedary, A. M. (2015): "La estructuración del espacio urbano y productivo de Gadir durante la fase urbana clásica: cambios y perduraciones", Complutum, 26 (1), pp. 225-242. Dor: http:// dx.doi.org/10.5209/rev_CMPL.2015.v26.n1.49351

Olivier, G. (1960): Practique antropologique. Paris: Vigot Freres. DoI: https://doi.org/10.1002/ ajpa. 1330210218

Quintero, P. (1910): "El Museo y la Biblioteca Provinciales", Boletín de la Comisión Provincial de Monumentos Históricos y Artísticos de Cádiz, año III, 13, pp. 33-34.

Quintero, P. (1915): Necrópolis ante-romana de Cádiz. Madrid: Hauser y Menet.

Quintero, P. (1917): Cádiz. Primeros pobladores: hallazgos arqueológicos. Cádiz: Imprenta de Manuel Álvarez.

Quintero, P. y De las Barras, F. (1913): Necrópolisfenicia de Cádiz y algunas medidas e indices de dos esqueletos hallados en las sepulturas fenicias de Cádiz. Cádiz: Imprenta de Manuel Álvarez.

Ramírez, J. R. (1982): Los primitivos núcleos de asentamiento en la ciudad de Cádiz. Cádiz: Ayto. de Cádiz.

Reverte, J. M. (1991): Antropología forense. Madrid: Ministerio de Justicia.

Rodes, R. (2004): "Foramen esternal vs orificio por proyectil de arma de fuego", Cuadernos de Medicina Forense, 35, pp. 71-74. Dor: http://dx.doi.org/10.4321/ S1135-76062006000200021

Rodríguez de Berlanga, M. (1888): "Sepulcros antiguos de Cádiz”, Revista Archeologica de Lisboa, II, pp. 33-49.

Ediciones Universidad de Salamanca / @®ఠ
Rodríguez de BerLanga, M. (1891): El nuevo bronce de Itálica. Málaga: Ambrosio Rubio. Disponible en http://www.bibliotecavirtualdeandalucia.es/catalogo/es/consulta/registro.cmd?id=1014055

Romero de Torres, E. (1934): Catálogo Monumental de España. Provincia de Cádiz. Madrid: Ministerio de Instrucción Pública y Bellas Artes.

Sánchez-Navarro y Neumann, M. (1890): "Estudio del sarcófago antropoide y esqueleto que contiene encontrado en Cádiz en 1887", Revista Archeologica de Lisboa, IV (1), pp. 16-24.

Santana, J. A. (2020): "Apuntes para el análisis e interpretación de contextos arqueológicos con restos óseos humanos", Revista Atlántica-Mediterránea de Prehistoria y Arqueología Sociales, 21, pp. 29-55, DOI: https://doi.org/10.25267/rev_atl-mediterr_prehist_ arqueol_soc.2019.v21.03

Steckel, R. H.; Larse, C. S.; Sciulli, P. W. y Walker, P. L. (2006): The Global History of Health Proyect. Data Collection Codebook. Ohio: Ohio State University.

Testut, L. y Latarjet, A. (1969): Tratado de anatomía humana. Barcelona: Salvat.

Toro y Quartiellers, C. Del (1901): Fenicios. Biblioteca del Artista Pintor. Cádiz: Tipografía gaditana, t. 1, pp. 87-91.

Torres, M.; Almagro-Gorbea, M.; López, M. E. y Mederos, A. (2010a): "El sarcófago masculino de Cádiz”. En Almagro-Gorbea, M. y Torres, M. (eds.): La escultura fenicia en Hispania. Madrid: RAH, pp. 22-37.

Torres, M.; López, M. E.; Mederos, A. y AlmaGRO-GORBEA, M. (2010b): "El sarcófago femenino de Cádiz”. En Almagro-Gorbea, M. y Torres, M. (eds.): La escultura fenicia en Hispania. Madrid: RAH, pp. 38-47.

UBELAKER, D. H. (1999; $3^{\text {rd }}$ ed.): Human skeletal remains. Excavation, analysis, interpretation. Manuals on archeology, 2. Washington: Smithsonian Institution. https://doi.org/10.1002/ajpa.1330800217

White, T. D. (2000; $2^{\text {nd }}$ ed.): Human osteology. San Diego-New York-Tokyo: Academic Press.

Yoldi, A.; Alemán, I. y Botella, M. C. (2001): "Funciones discriminantes del sexo a partir del ilion en una población mediterránea de sexo conocido", $R e-$ vista Española de Antropología Física, 22, pp. 23-38. Disponible en https://www.seaf.es/index.php/revista-reaf/33-volumen-22-2001 